University of Rhode Island

DigitalCommons@URI

Open Access Master's Theses

2020

\title{
THE DEVELOPMENT AND EVALUATION OF TRANSGENIC SORGHUM LINES FOR CONFERRED PHENOTYPES
}

Jiayin Liu

University of Rhode Island, 604423639@qq.com

Follow this and additional works at: https://digitalcommons.uri.edu/theses

\section{Recommended Citation}

Liu, Jiayin, "THE DEVELOPMENT AND EVALUATION OF TRANSGENIC SORGHUM LINES FOR CONFERRED PHENOTYPES" (2020). Open Access Master's Theses. Paper 1873.

https://digitalcommons.uri.edu/theses/1873

This Thesis is brought to you for free and open access by DigitalCommons@URI. It has been accepted for inclusion in Open Access Master's Theses by an authorized administrator of DigitalCommons@URI. For more information, please contact digitalcommons-group@uri.edu. 


\section{THE DEVELOPMENT AND EVALUATION OF TRANSGENIC SORGHUM \\ LINES FOR CONFERRED PHENOTYPES}

BY

JIAYIN LIU

A THESIS SUBMITTED IN PARTIAL FULFILLMENT OF THE REQUIREMENTS FOR DEGREE OF MASTER OF SCIENCE

IN

CELL AND MOLECULAR BIOLOGY

UNIVERSITY OF RHODE ISLAND 


\section{MASTER OF SCIENCE THESIS}

$\mathrm{OF}$

JIAYIN LIU

\section{APPROVED:}

Thesis Committee:

Major Professor: Albert P. Kausch

Joel M. Chandlee

Alison W. Roberts

Brenton DeBoef

DEAN OF THE GRADUATE SCHOOL 


\section{ABSTRACT \\ Agrobacterium-mediated transformation of sorghum (Sorghum bicolor)}

requires minimally 9-months from wild type immature embryo explants to T0 seeds.

More efficient methods for sorghum transformation are necessary to conduct routine transgenesis for genome editing purposes in this important crop. With this in mind, there were two primary objectives to this thesis. The first was to evaluate and possibly improve upon methods for characterizing putative transformants once produced through Agrobacterium-mediated transformation of sorghum. The second was to evaluate and possibly improve upon transformation efficiencies in sorghum using an available Cas9 construct that would provide, long-term, a platform in sorghum for gene editing purposes. The first objective was addressed by evaluating a previously generated transgenic sorghum line designed to improve overall grain yield through the introduction of a maize silkless gene $(s k 1)$ construct. The maize silkless gene was first used in maize by Hayward et al., 2016 to produce transgenics that conferred feminization on maize male flower by down regulating the jasmonic acid synthesis pathway. The same construct SK1 $\Delta$ SVL:Citrine:SVL used in Hayward et al., 2016 was used to transform sorghum based on the understanding of high homology between the sorghum and maize genomes. Through a series of analyses, the presence and expression of SK1 $1 \Delta$ SVL:Citrine:SVL was confirmed, but the predicted phenotype of flower feminization and improved yields was not observed in $\mathrm{T}_{1}$ transgenic sorghum lines. The second objective was designed to introduce into sorghum a vector containing $\operatorname{Cas} 9$ to test the stable expression of Cas9 for genome editing in transgenic lines. The first step towards this objective was to generate and characterize the 
required transgenic lines and appropriate controls. The pNG111ZmUbi::TaCas9_PvUbi::1GFP construct was used to integrate TaCas9 into the wild type BTx430 sorghum genome and molecularly characterize these events. The pNG108PvUbi::1GFP construct served as a negative control for pNG111 since it is lacking the TaCas 9 cassette. Both constructs contain constitutively expressed $m G F P$ which is detected as a visible reporter, and the bar gene served as a selectable marker conferring resistance to the herbicide bialaphos. In addition, transgenic lines for both constructs were molecularly characterized by PCR, Southern blot analysis, and the 'paint assay' to detect the functional expression of the bar gene. Functional analysis of the stably integrated $\operatorname{TaCas} 9$ will be conducted in future studies. By analyzing the newly developed transgenic sorghum lines with constitutively expressed $\operatorname{TaCas} 9$, we hope to contribute to the development of a new platform for genome editing in sorghum. 


\section{ACKNOWLEDGMENTS:}

I would like to thank Dr. Albert Kausch for his guidance and mentoring during the time I worked on this project. His tremendous support and patience helped me achieve the goals of my Master's thesis. I would also like to thank my committee members, Dr. Joel Chandlee and Dr. Alison Roberts for their support and suggestions. Lastly, I would also like to thank Dr. Brian Maynard for serving as the chair of my thesis defense.

I appreciate all of the help and support provided by the members of Dr. Kausch's lab, namely, Kimberly Nelson-Vasilchik and Joel Hague. Their expertise in plant transformation and molecular analysis approaches allowed them to coach me and support me in my progress through this research project.

I would like to thank my family for their support and understanding during the stressful time in my life as I attempted to obtain this advanced degree.

Chapter 1 in my thesis is developed from collaboration with Dr. Stephen Dellaporta's lab in the Department of Molecular, Cellular \& Developmental Biology at Yale University. Chapter 2 in my thesis evolved from a collaboration with Dr. Daniel Voytas' lab in the Department of Genetics, Cell Biology and Development at the University of Minnesota. 


\section{TABLE OF CONTENTS}

PAGE

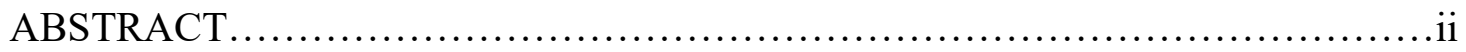

ACKNOWLEDGMENTS .....................................................

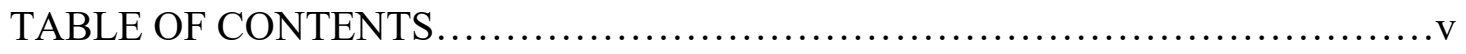

LIST OF FIGURES ...................................................vii

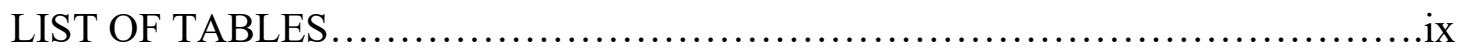

LITERATURE REVIEW ................................................... 1

Plant Transformation....................................................

Genome Editing................................................8

CRISPR/Cas9..............................................10

Sorghum Transformation.......................................... 14

CHAPTER 1: SEX DETERMINATION IN SORGHUM........................ 17

Introduction........................................................ 18

Methods........................................................20

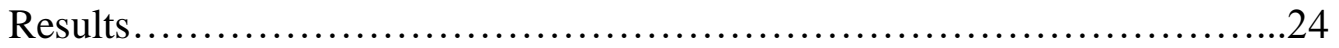

Discussion........................................................

CHAPTER 2: THE DEVELOPMENT OF TRANSGENIC SORGHUM WITH

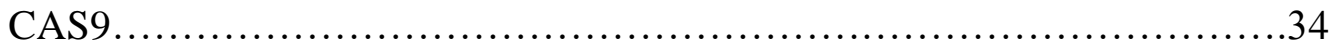

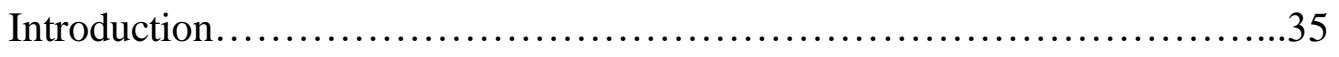

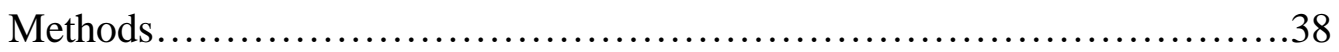

Results.....................................................41

Discussion....................................................46 
APPENDICES.

BIBLIOGRAPHY 


\section{LIST OF FIGURES:}

PAGE

Figure 1. Schematic of Agrobacterium-mediated transformation....................6

Figure 2. (A) Schematic of CRISPR/Cas9 in vivo and (B) Function domain of Cas9

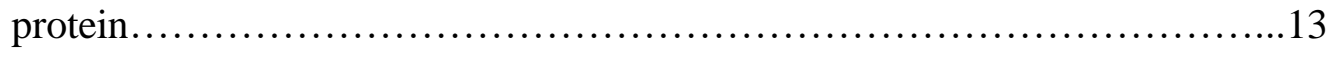

Figure 3. Representative timeline for standard sorghum transformation............16

Figure 4. The $s k 1$ transgene (pYU2996 SK1 $\Delta$ SVL:Citrine:SVL) construct .........23

Figure 5. 'Paint Assay' for pYU2996 transformants...............................24

Figure 6. PCR result for the presence of the bar gene cassette.....................26

Figure 7. PCR result for the presence of the citrine gene cassette..................26

Figure 8. Southern blots for determination of bar gene copy number..............27

Figure 9. Confocal images of E. coli expressing Citrine (A) and E. coli negative

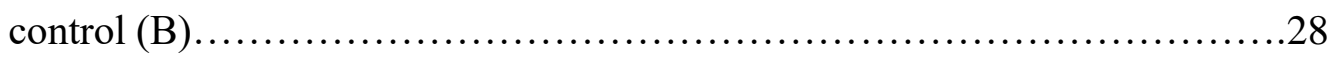

Figure 10. Confocal images of sorghum expressing Citrine (A) and sorghum negative

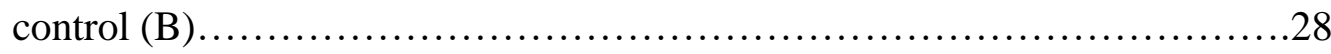

Figure 11. Dissecting light scope images of pYU2996 SK1 $\Delta$ SVL:Citrine:SVL PCR positive inflorescence (Top row) and negative control (Bottom row)..........30

Figure 12. The inflorescences of pYU2996SK1 $\Delta$ SVL:Citrine:SVL positive plants (A) 
and pYU2996SK1 1 SVL:Citrine:SVL negative plants (B).... .31

Figure 13. T-DNA in pNG111-ZmUbi::TaCas9_PvUbi::1GFP 38

Figure 14. T-DNA in pNG108PvUbi::1GFP 38

Figure 15. Developing transgenic callus on regeneration medium. 42

Figure 16. 'Paint Assay' for pNG111\&pNG108

Figure 17. PCR analysis for the bar gene cassette in To transgenic sorghum transformed with pNG111 confirmed using bar primers (see Appendices)....43

Figure 18. PCR test for $g f p$ gene cassette . .44

Figure 19. PCR test for $\operatorname{Ta} \operatorname{Cas} 9$ gene cassette. 44

Figure 20. Southern blot for pNG111 construct copy number...................45

Figure 21. GFP expression analysis ...................................... 46

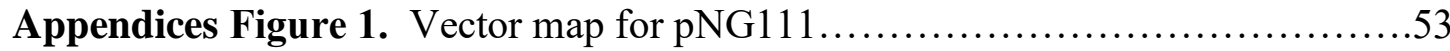

Appendices Figure 2. Vector map for pNG108..............................54 


\section{LIST OF TABLES:}

PAGE

Table 1. Sorghum transformation results with $\mathrm{pNG} 111$ and $\mathrm{pNG} 108 \ldots \ldots \ldots \ldots . . . .42$

Appendices Table 1. Media Specifications Used for Sorghum Transformation..51-52

Appendices Table 2. PCR Primer Specifications Used to Analyze for the bar, citrine,

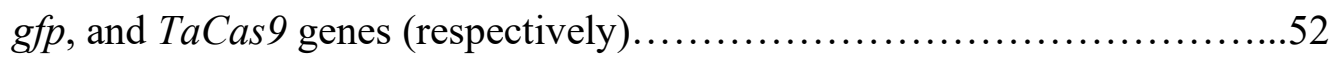




\section{LITERATURE REVIEW}

\section{Plant Transformation}

The development of genome editing applications through the use of plant transformation technology in cereal crops is critical for future crop improvement. This is a required technology to develop and analyze genome modified plants. Plant transformation is used to introduce valuable transgenes into the plant genome, followed by the recovery of regenerated, fertile plants with stably integrated transgenes that confer trait enhancement or improvement. Improvements on existing transformation technologies would ideally allow for genotype independent and almost tissue culture free strategies. Improvements in current plant transformation technology are both required and necessary to functionalize genomic analyses through genome editing. This is essential to functionally link genes to biological processes that would allow for the modification of existing metabolic pathways.

Crop improvement strategies based on biotechnology strategies will require concurrent advances in plant genomics including advanced genomics for gene annotation and functional analysis and genome editing through plant transformation (Kausch et al. 2019; Council for Agricultural Science and Technology (CAST), 2018; Altpeter et al. 2016). In fact this very topic has been the subject of intensive review over the past several years (Songstad et al. 2017). Robust genomics and computational biology tools provide ways to identify target sequences for genome editing. Further, advanced genome editing approaches then allow for desired modifications in a target species genome, such as, single base pair change, insertions and deletions (Council for 
Agricultural Science and Technology (CAST), 2018; Songstad et al. 2017). The application of these technologies is highly dependent on the capability to recover fertile genome modified plants. Plant transformation for any cereal species or variety will make possible direct gene analysis, targeted trait modification and provide a new basis for the application of the principles of synthetic biology.

Standard plant transformation protocols can be applied to knock-out (down) gene expression, make specific adjustments in protein structure and function, and observe over-expression and ectopic characteristics as an enabling technology in basic plant biology. However, the limitations of current standard plant transformation protocols have created a daunting bottleneck for functional genomic analyses and genome editing (Altpeter et al. 2016). Ideally, plant transformation should not be limiting with regard to plant species, genotype or explant source. An additional preference is that the technology be untethered, as much as possible, to reliance on tissue culture. The improved technology should be able to efficiently modify any genomic sequence in any variety and efficiently produce stably heritable events. With increasing global human population growth and food consumption, many research efforts have focused on biotechnology based crop improvement to overcome the previous issues for sustainable agriculture (Jiao et al. 2018). Plant transformation is a major challenge and bottleneck for creating the transgenics and the recovery of genome edited events for functional genomics. The role of plant transformation is central to introducing specific DNA components, or genome editing of specific gene targets to recover stable, heritable genetic events. The gene modified plants will express the stable and heritable events of interest which can then allow for phenotypic 
characterization for their conferred traits. However, the regeneration ability still exists as a significant bottleneck for most plant species to allow for efficient plant transformation (Altpeter et al. 2016).

Even if the related approaches have been well developed to transfer DNA into a single plant cell that can be regenerated into a whole, intact transgenic plant, plant transformation protocols still contain limiting parameters, as described previously, including genotype dependence and low or no regeneration efficiency in several important crop species. Moreover, some plant tissues are difficult to obtain as usable plant transformation explants (e.g., immature embryos or immature inflorescences). Therefore, these bottlenecks prevent the accessibility and transfer of technologies from academic laboratories in the public sector.

Plant transformation technology has been a well-recognized challenge for decades (Altpeter et al. 2016) and the technology has been incrementally improved upon over a long period on time. However, the current state-of-the-art is still ineffective for many crops, because current plant transformation requires an appropriate genotype, experienced labor, improvements for low frequencies, more efficient editing tool and huge screening efforts for inconsistencies of gene expression. Crop functional genomic research suffers from specific plant species that are recalcitrant to plant transformation (Altpeter et al. 2016; Kausch et al. 2019). Therefore, efficient Agrobacterium-mediated transformation is typically applied to a small range of plant species. One of the major challenges is the long tissue culture periods that are used to cultivate modified cells and tissues to transgenic plants. This extended tissue culture period has resulted in many obstacles for generating transgenic 
and genome edited plants. Even though the tissue culture takes a long time to produce the transformed events, the frequency is low for engineered tissues to regenerate stably in many plants and cultivars.

There are two DNA delivery methods which are predominately used to edit organisms in most academic and industry laboratories: Agrobacterium-mediated transformation and particle bombardment-mediated gene delivery. The current transformation protocols for most plants currently require extensive tissue culture, but it is important to simplify and optimize the protocols for all crops to allow for wider application.

The complete systems for developing plant transformation technologies must be comprehensive, since it has involved the understanding of molecular biology, plant tissue culture, plant physiology and plant developmental biology (Kausch et al. 2019). However, the difficulties inherent in plant transformation are often underappreciated even though the technology provides the fundamental platform to develop transgenic organisms. The transgenic plants created provide the basis for analysis of conferred trait genetic value, basic plant biology, improve the metabolic pathways in plants, and produce stable resistance to environmental or biotic stress. For example, transgenic plants can express genes which confer resistance to herbicides (Devos et al. 2008) and viral or microbial pathogens (Ferreira et al. 2002). It is almost impossible to efficiently produce innovative improvement on plant traits, plant gene discovery, and functional genomics without plant transformation technologies.

Agrobacterium infection and gene transfer to plant cells has been well studied for the past three decades (Altpeter et al. 2016). A general schematic for 
Agrobacterium infection and gene transfer to plants is shown (Figure 1). When the plant cells are injured, especially the dicot, the response is secretion of phenolic compounds, including acetosyringone. Agrobacterium responds to these signals through the VirA/VirG two-component sensing system which will stimulate the expression of the virulence (vir) genes (Altpeter et al. 2016). In this set of vir genes, virD1 and virD2 will combine together and form specific nucleases to cut the T-DNA region between the borders in the Ti plasmid in Agrobacterium. Recently designed binary vectors are capable of delivering the T-DNA containing any gene construct of interest including genome editing components. When the T-DNA region is excised out from the Ti plasmid, the VirD2 proteins will bind to the single-strand T-DNA and direct transfer of the T-DNA into the infected plant cell via the type IV secretion system. In the plant cell, the single DNA binding protein VirE2 covers and protects the T-DNA/VirD2 strand (Altpeter et al. 2016). The complex, formed by TDNA/VirD2 strand with VirE2 and other plant proteins, can target the nucleus. Once the T-DNA is transferred into the nucleus, proteins will be dissociated from the TDNA strand. The transferred T-DNA is then replicated to form double-stranded DNA which is in a non-integrated form (transient transformation). After integration into the plant genome, the T-DNA forms a stably transgenic cell which can be selected through the use of selectable markers, such as bar, hra, als, hpt and others (Kausch et al. 2019). The next step in the process is to regenerate these cells to fertile transgenic plants capable of use for breeding purpose (Altpeter et al. 2016). 


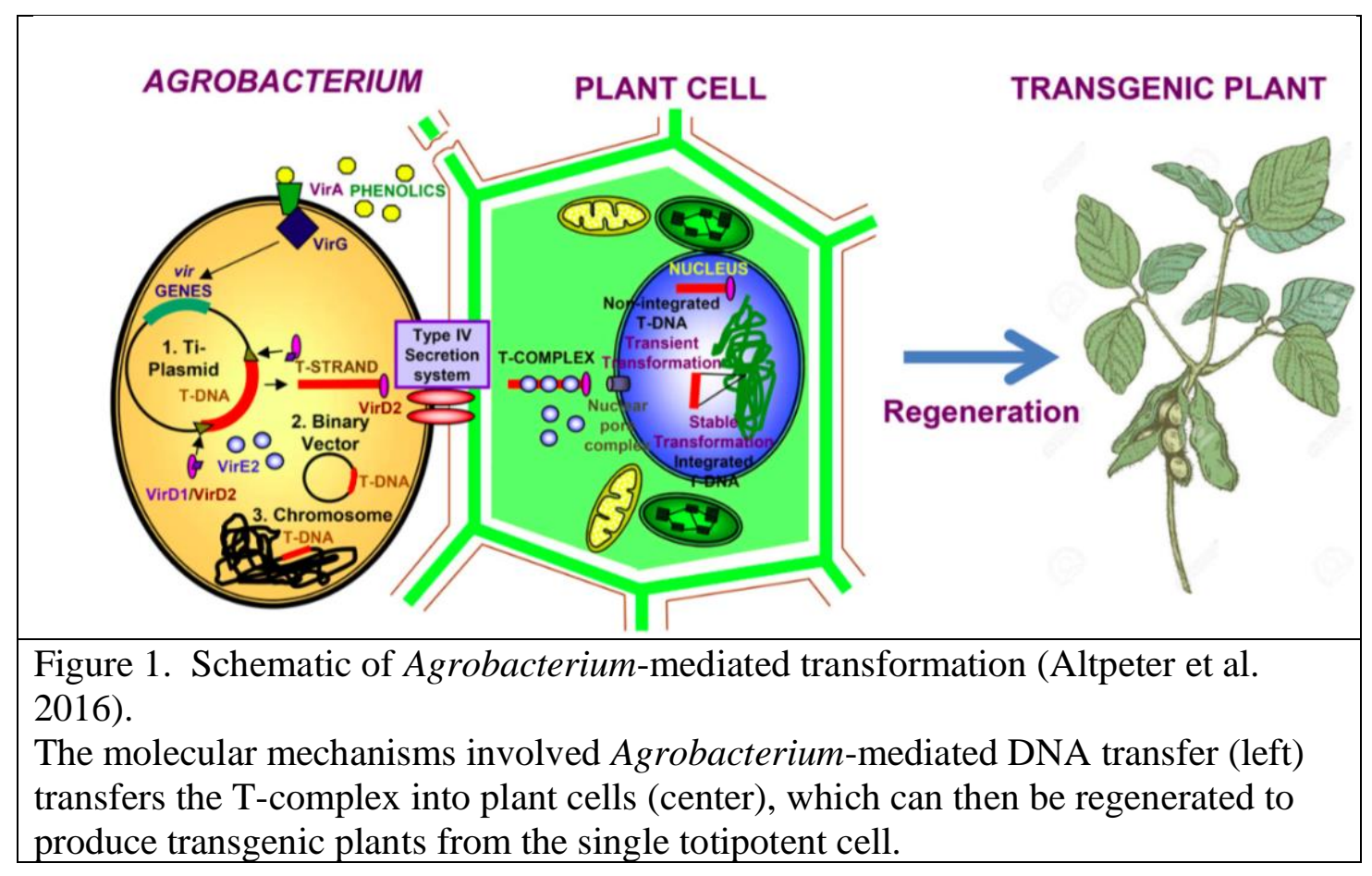

Agrobacterium tumefaciens has been the subject of research for decades [reviewed by: (Altpeter et al. 2016; Kausch et al. 2019)]. Early work on Agrobacterium dates to the early 1940s with investigations on its plant pathogenicity as the causative agent for crown gall disease. In 1977, Agrobacterium DNA transfer to plant cells was reported via Agrobacterium Ti plasmid (Altpeter et al. 2016). The Ti plasmid contains the T-DNA which is imported into the plant to nucleus, but designed and engineered DNA constructs could not at that time be integrated into Ti plasmid. The genes involved with pathogenesis were removed (Fraley et al. 1983) to create a disarmed Ti plasmid which could be subsequently engineered (Fraley et al. 1983). Then, the binary vector in Agrobacterium-mediated transformation was developed after the expression of bacterial genome was reported in plant cell (Kausch et al. 2019). The developed binary vector was used to transfer foreign DNA into plant cells, which was able to stably genetically modify the plant genome (De Block et al. 1984). In the 
binary vector system, antibiotic resistance genes were used to select the transformed organism from non-transformed groups and various promoters were explored to drive the expression of the inserted gene(s) (Bevan et al. 1985).

The early plant transformation systems required Agrobacterium-mediated gene delivery, which contain the tissue culture system for the DNA delivery, transformant selection and plant regeneration. However, the initial plant transformation systems were not able to be used with monocotyledonous plant. Even though extensive research efforts to develop plant transformation systems for monocots (Kausch et al. 2019), stable gene delivery through Agrobacterium and recovery of fertile transgenic plants was not accomplished. In a very innovative approach to overcome this obstacle to the gene transfer barriers, John Sanford and Ted Klein invented 'the Gene Gun' (microprojectile bombardment) in 1987 (Kausch et al. 2019) as an alternative to the Agrobacterium-mediated method (Kausch et al. 2019). In 1988, the first transgenic monocot plant was produced by microprojectile bombardment (Kausch et al. 2019). This direct DNA delivery method also eliminated the difficult and ineffective protoplast systems for maize transformation, an agronomically important monocot species. This technology was then applied successfully for the transformation of many cereals, but it also had several drawbacks, including: 1. gene silencing by multicopy gene insertion; 2. non-essential DNA insertions, such as the gene construct plasmid backbone; and 3. truncated or rearranged transgene cassette integration. The biolistic technology brought a novel approach to plant transformation, and produced significant research on basic plant biology and gene regulation. Eventually and fortunately, the Agrobacterium-mediated transformation methodology was improved upon and 
extended to successfully recover transgenic monocot plants. This was accomplished in 1995 by researchers at Japan Tobacco by modification of the virulence genes to create super-virulent Agrobacterium strains which were capable of infecting and transferring DNA to monocot species. These super virulent strains have in turn, been modified and improved over the years to result in highly effective gene transfer methods now applicable to most monocots (Kausch et al. 2019).

In conclusion, plant transformation is a critical platform for the development of genome editing and transgenic genome engineering in plants. Furthermore, the Agrobacterium-mediated and microprojectile bombardment transformation systems remain as the most the reliable approaches for plant transformation for most plants. The main processes for plant transformation can be summarized in three critical steps: 1. the specific DNA delivery and integration into recipient cells; 2. selection of the successful stable integrant; and, 3. the regeneration of the transgenic plant from a single transformed totipotent cell to a fertile plant. The specific transformation protocols are variable depending on the unique features of monocots and dicots, which will be an important foundation for further development of functional genomics in both monocot and dicot plants.

\section{Genome Editing}

Extensive and time consuming conventional breeding programs produce the bulk of the varieties used for most of our current commercial crop plant production, the remainder being only a few undomesticated wild plants being used for crop production. All of the human food supply is produced from domesticated organisms 
that are either naturally occurring mutants or the result of selection for desirable traits that confer environmental and yield advantages (Meyer et al. 2012). After early stages of plant domestication and selection of mutants through conventional breeding, mutational techniques were developed to promote higher frequencies of mutations and increased the efficiency of the selection stages for new varietal development. These induced mutation techniques include chemical mutagenesis such as EMS, physical mutagenesis, such as various radiation techniques, and the insertional mutagenesis such as transposon or gene tagging. Induced mutagenesis has successfully produced over 3200 officially released new varieties (FAO/IAEA 2014). Nonetheless, more efficient and precise techniques are still needed for increasing production levels.

New gene editing tools have been developed and used to efficiently edit genomic sequence in different species [reviewed in: (Weeks et al. 2016).; and, (Songstad et al. 2017)]. For application of most gene editing tools, their editing function is dependent on how to identify and target specifically the desired sequence in the target genome. In order to accurately recognize a target sequence, site-directed nucleases (SDNs) would be used to recognize the target sequence. The SDNs directed system would make double stranded breaks (DSBs); then, DSBs would be repaired by endogenous non-homologous end joining (NHEJ) or homology-directed recombination (HDR). Typically, NHEJ would make some small sequence deletions or insertions which may result in genetic change at the target site. There have been several gene editing approaches that have been developed using SDNs, such as, meganucleases (Gao et al. 2010), Zinc Finger Nucleases (ZFNs) (Shukla et al. 2009), Transcription Activation-Like Effector Nucleases (TALENs) (Clasen et al. 2015) and 
Clustered Regularly Interspaced Short Palindromic Repeats (CRISPRs) (Jinek et al. 2012). Currently, the CRISPR system is preferred and has been widely applied in academic research laboratories and industry. The CRISPR system has been developed from naturally occurring defense mechanism in Steptococcus pyogenes (Jinek et al. 2012; Cong et al. 2013; Mali et al. 2013). Compared to ZFN and TALENs, both of which use a protein to recognize the target DNA sequence, the CRISPR system is more precise and easier to apply in genomic research because RNA was used to recognize the target DNA sequence (Sander and Joung 2014; Schiml and Puchta 2016). The CRISPR system has been successfully applied in a wide range of plant species for genomic modifications (Jinek et al. 2012; Cong et al. 2013; Mali et al. 2013). Advanced genome editing provide a significant opportunity for modern plant breeding, which provides multiple directions for phenotypic improvements in plants (Bortesi and Fischer 2015; Jiang et al. 2013).

\section{CRISPR/Cas9}

Clustered regularly interspaced short palindromic repeats (CRISPR) along with CRISPR-associated proteins represent components of microbial defense mechanisms found in most Archaea and many Eubacteria. This is a mechanism to defend against viral and plasmid cellular invaders (Thurtle-Schmidt and Lo 2018). The CRISPR component contains many non-contiguous repeats and spacers, spacers are foreign genome elements (Figure 2A; blue and green elements) between repeats (Figure 2A). During the evolutionary adaptation of this mechanism, Archaea and Eubacteria achieve a cellular memory of the invading virus or plasmid (some pieces of foreign 
DNA), and these pieces of foreign DNA are integrated into the CRISPR genomic locus. When CRISPR incorporates a foreign sequence, the system allows for the production of a target RNA, termed crRNA that can direct the Cas9 protein to bind to foreign target DNA (invaders) and cleave the sequence (Figure 2). Because crRNA recognizes some nucleotide sequences of the invader, it can direct Cas9 proteins to bind specifically to the DNA of invaders instead of itself (Thurtle-Schmidt and Lo 2018). The CRISPR systems contain 3 types of mechanism, type I and III are found in both bacteria and archaea, type II is found only in bacteria. Type I contains the Cas 3 gene that encodes a large protein with divergent helicase and DNase activities. Type III contains polymerase and RAMP (repeat-associated mysterious proteins) modules. The RAMP superfamily does not present an autonomous functional unit but it can catalyze the processing of the long spacer-repeat-containing transcript into the mature crRNA (Thurtle-Schmidt and Lo 2018). The type II mechanism of the CRISPR/Cas9 system is best adapted to use for editing because it requires just one Cas9 protein and two RNA components. Before generating of crRNA, the CRISPR sequence is transcribed and combined with the foreign sequence to form pre-crRNA (Figure 2). The upstream portion of the CRISPR sequence is also transcribed. This is termed the trans-activating CRISPR RNA (tracrRNA). The tracrRNA can be complementary to the repeat region in the CRISPR sequence. It will bind with pre-crRNA to form a double-stranded RNA. Rnase III will recognize and cleave this double-strand RNA to form crRNA: tracrRNA (contain one spacer) complex. When this complex combines with Cas9 protein, the Cas9 protein can be activated to cleave a targeted DNA sequence (Thurtle-Schmidt and Lo 2018). 
To function properly the Cas9 protein needs to recognize the protospaceradjacent motif (PAM) first. Cas9 contains two domains to cleave the targeted DNA sequence (Figure 2B). One is the HNH domain that is complementary to crRNA; another is the RuvC-like domain that is not complementary to crRNA. However, designed single guide RNA can bind the crRNA and tracrRNA complex. This modified CRISPR/Cas9 system is much simpler to design, compared to either TALENs or ZFNs, for gene editing purposes. It is easier to construct DNA vectors than having to design the protein binding domains of TALENs and ZFNs. The induced sgRNA and Cas9 protein can make multiple double-strands break simultaneously, resulting in enhanced mutagenesis and gene editing. However, the modified CRISPR/Cas9 system also has been limited by the restriction of target sequence, large protein size and off-target mutation (Thurtle-Schmidt and Lo 2018). The PAM site is the main limitation for selection of a target sequence and different bacterial species have different PAM sites for the Cas9 protein. Scientists have created a Cas9 variant, namely SpCas9, that can recognize a different PAM site (Nakade et al. 2017). Another use of SpCas9 is an RNA-targeting Cas9 (Rcas9) system, which requires a PAMpresenting oligonucleotide hybridizing with a target single-strand RNA to act as PAM motif (Nakade et al. 2017). 


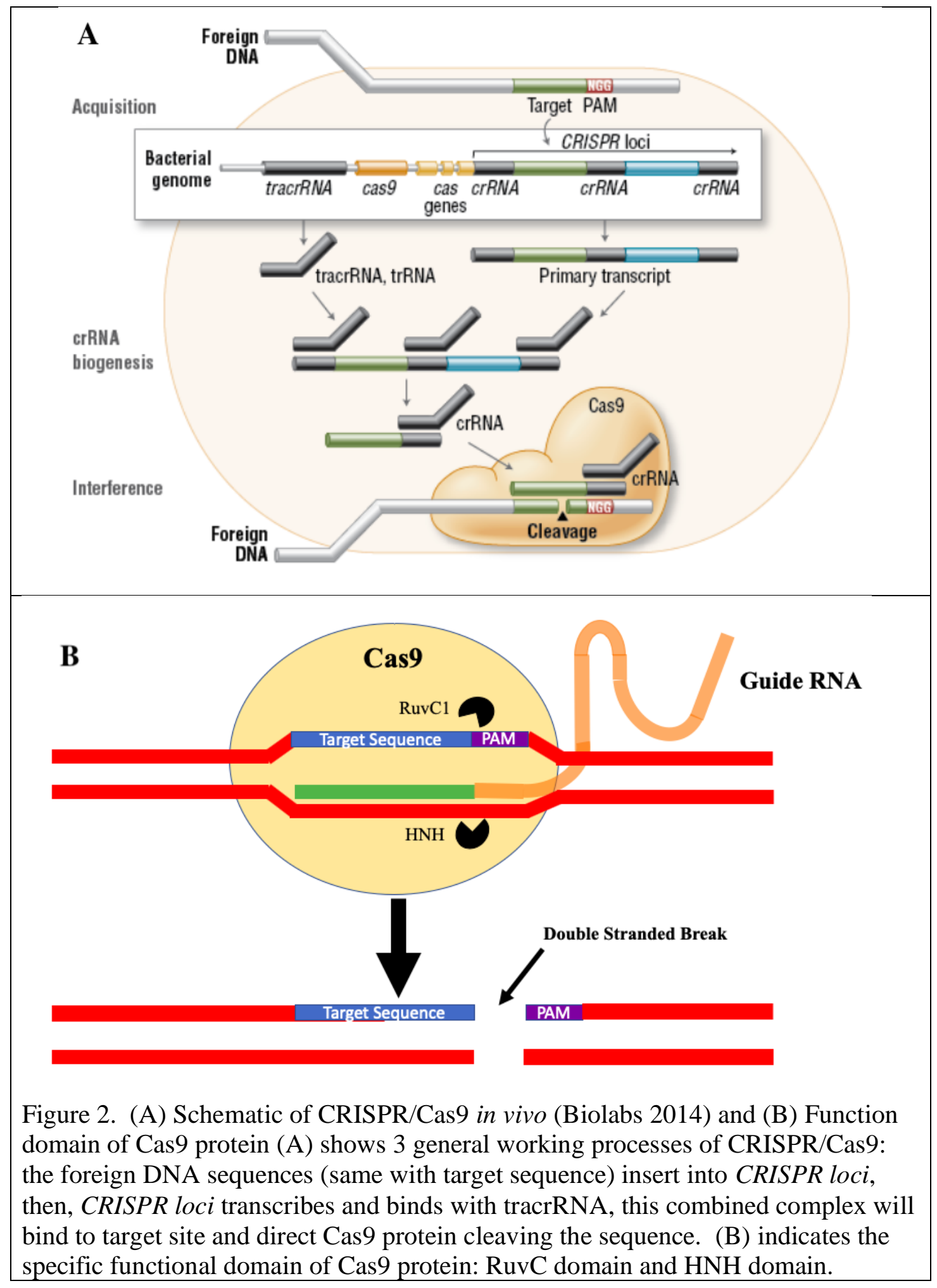




\section{Sorghum Transformation}

The fact that cereal crops are important to global agriculture, food security, world economy, and international stability is well documented and widely understood (Belide et al. 2017). Sorghum (Sorghum bicolor) represents the third largest cereal crop in the world and the fifth largest in the US (Belide et al. 2017; Jiao et al. 2018). The grain is widely used for food, animal fodder and biofuels (Jiao et al. 2018). Application of modern biotechnology approaches for genetic improvement of sorghum is important to expand agricultural uses for this crop and address basic biological questions. Biotechnology approaches include advanced genomics, transgenics, and genome editing leading to improvement in traits such as enhanced yields, insect and pest resistance, abiotic stress tolerance, and increased nutrition. Basic biological questions, including genetic control of plant development, water use efficiency and photosynthesis can also be evaluated. In order to accomplish these goals, a reliable and robust plant transformation protocol is a fundamental requirement.

The protocols for sorghum transformation are well established (Figure 3). While protocols for sorghum transformation are well established, they are still not routine and subject to low efficiencies. The beginning of sorghum transformation requires large scale sorghum cultivation of wild type plants for donor material to provide enough immature embryos for continuous sorghum transformation. Also, the need for a constant supply of immature embryos requires intensive and expensive labor. However, while most research suggest that immature embryos are ideal explants over others for plant transformation (Belide et al. 2017; Wu et al. 2014), other explants, such as leaf material are currently being explored. The need for healthy and vigorous 
immature embryos as explants has significance for transformation efficiency since they influence the embryogenic callus induction (Zhao et al. 2000). The transgene can be transferred into isolated immature embryos via Agrobacterium-mediated transformation or particle bombardment. The particle bombardment has several drawbacks (as previously described); therefore, Agrobacterium-mediated transformation has become the main approach for the sorghum transformation for routine trait manipulation. The transformed cells in sorghum immature embryos are selected from non-transformants and regenerated to complete fertile sorghum plant. However, some negative tissue culture factors, including the accumulation of phenolic compounds and continuous sub-culture, will gradually decrease the poor regeneration efficiency (Belide et al. 2017). The entire sorghum transformation protocol requires 9 to 12 month from the wild type sorghum embryos to the To gene modified sorghum fruit. Therefore, routine and robust sorghum transformation protocols are essential for investigating fundamental questions.

There are some challenges for sorghum transformation. The stable and continuous sorghum plant supply is required to provide appropriate explant for transformation experiments. Tissue culture is an essential step in sorghum transformation and also the need for experienced labor and corresponding facilities. The efficiency of transformation always suffers from genotype dependence, long tissue culture time and callus culture intermediates. These challenges interfere with the necessary enhancement of efficiency for sorghum transformation. In comparison, advances in genomics and gene editing approaches have shown tremendous progress. Recently, a breakthrough in monocot transformation provided an opportunity for the 
improvement of sorghum transformation. BABY BOOM ( $B B M)$ AND WUSCHEL (WUS2) was confirmed as transcription factors genes, which are involved in somatic embryogenesis (Mookkan et al. 2018; Mookkan et al. 2017; Nelson-Vasilchik et al. 2018). The expression of $B B M$ and WUS2 produce morphogenic regulators that can induce efficient somatic embryogenesis. Their use in transformation constructs could potentially improve the efficiency of transformation for sorghum and some other recalcitrant plant species (Lowe et al. 2018; Lowe et al. 2016; Nelson-Vasilchik et al. 2018). Necessary improvements for sorghum transformation efficiency can allow for improvements in strategies for sorghum genomic modifications of agriculture importance.

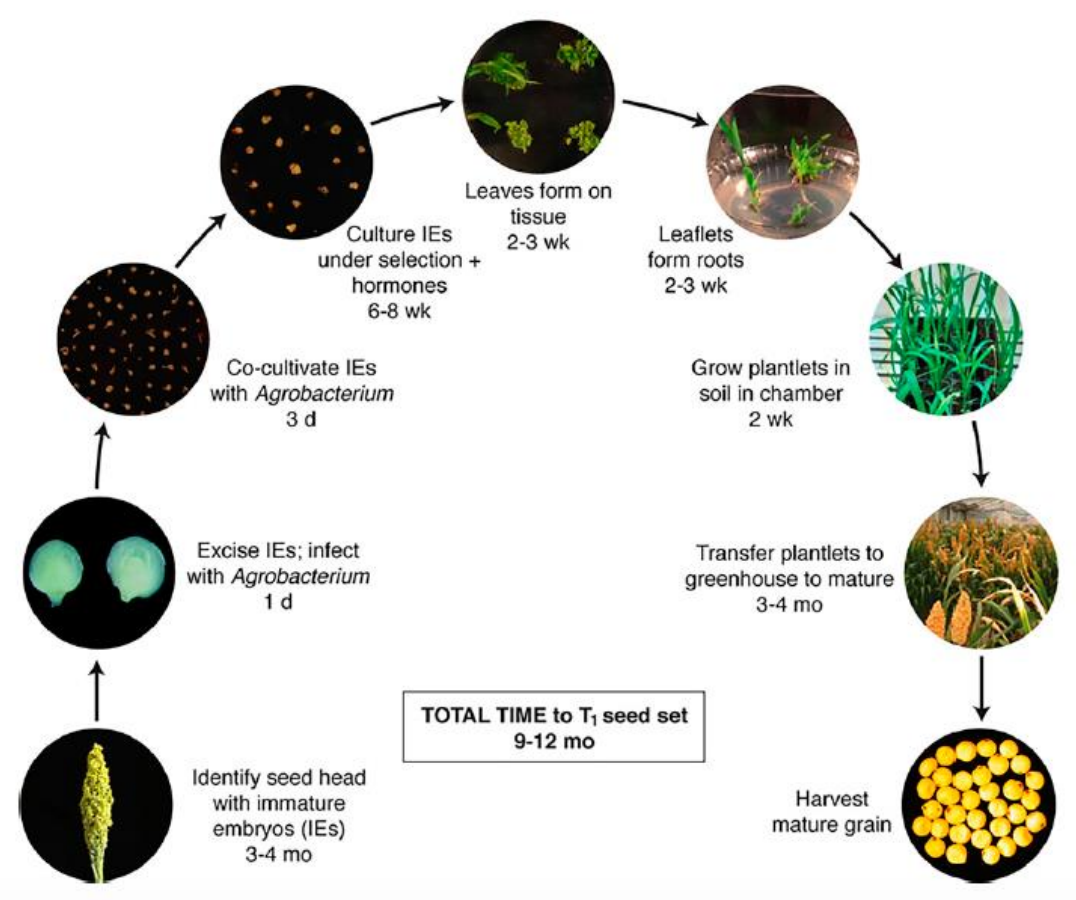

Figure 3. Representative timeline for standard sorghum transformation (Altpeter et al. 2016).Sorghum immature embryo explants (12 days post pollination, are used for plant transformation; the entire procedure starting from the bottom left corner to bottom right corner requires 9 to 12 months, and each part of the procedure is shown with the corresponding time. 


\section{CHAPTER 1: SEX DETERMINATION IN SORGHUM}




\section{Chapter 1: Sex Determination in Sorghum}

\section{Introduction:}

Cereal crops that feed the world include rice, maize, sorghum, wheat, barley, oats and other minor cereal crops such as fonio and teff. Morphologically and genetically the cereal crops share significant homology, therefore, discovery of a gene in one of them has potential application as an orthologue in another. The silkless 1 $(s k 1)$ gene of maize is known to play a key role in sex determination (Hayward et al. 2016). It is, therefore, plausible that a gene from maize could function in sorghum and carry out a similar function. There are many examples where across broad species orthologous genes have functioned well (Hayward et al. 2016), as well as a few where they do not.

Maize and sorghum are both hermaphroditic plants with similar flower morphologies, but not identical. Maize flowers are unisexual while sorghum flowers are bisexual. Having unisexual flowers is highly advantageous in hybrid crop production and the $s k l$ gene may be the key distinguishing feature giving rise to maize and sorghum flower structure differences (Hayward et al. 2016).

The $s k 1$ gene has been characterized in the sex determination pathway in maize (Hayward et al. 2016). The sex determination pathway in maize and sorghum is complicated because several genes and phytohormones are involved. In particular, in maize, silkless 1 (sk1), TASSELSEED 1 (TS1), and TASSELSEED 2 (TS2) are important in sex determination and influence each other (Li and Liu 2017). The TS2 generates cell death signals for the pistil and TS1 controls the expression of TS2. 
Moreover, both of them contribute to biosynthesis of jasmonic acid (JA) that is involved in pistil elimination and plays a key role in the developing stamen. The $s k 1$ gene product is a protector for pistil formation because it prevents pistil elimination mediated by JA (Li and Liu 2017; Hayward et al. 2016). Therefore, it was hypothesized that enhanced expression of the maize $s k l$ in transgenic sorghum may influence sex determination for sorghum in a similar developmental pathway to what is observed in maize.

Maize is monecious with flowers that are initially bisexual. The maize sex determination system results in inflorescences with imperfect florets, the tassel and the ear, through organ arrest. Genetic analysis has shown that the expression of the $s k 1$ is required to protect pistils in ear spikelets from tasselseed-mediated elimination. Recent studies by (Hayward et al. 2016) in maize showed that plants transformed with a sk1 transgene (SK1 $\Delta$ SVL:Citrine:SVL) driven by a constitutive cauliflower mosaic virus (CaMV) 35S promoter displayed a pistillate phenotype, where the tassel inflorescence was completely feminized. The SVL domain is a putative peroxisomal targeting sequence. The reporter, citrine, was demonstrated to localize to peroxisomes (Hayward et al. 2016). These results indicate that $s k l$ expression is sufficient and necessary to block the tasselseed-mediated elimination of pistils in both ear and tassel spikelets, resulting in a completely feminized plant. This implies a mechanism of $s k 1$ protection by prevention of jasmonic acid mediated pistil elimination (Hayward et al. 2016). Many related grasses, such as sorghum, develop two types of flowers on a panicle: one of these, known as the sessile spikelet (SS) is fertile and develops seeds; the other type called pedicellate spikelets (PS) do not make seeds. Single-copy 
orthologs of $s k 1$ have been identified in sorghum, although the SS florets are perfect because they are fertile and produce seed (bisexual). It is hypothesized that constitutive overexpression of the maize $s k l$ in sorghum could result in seed production in PS. It is also known that the $m s d l$ gene in sorghum (Jiao et al. 2018) participates in the jasmonic acid pathway and mutants result in rescued pedicellate flowers.

Using the same vector as in the maize experiments (35S:SK1 $\triangle \mathrm{SVL}:$ Citrine:SVL), 26 To independent events were generated via Agrobacterium-mediated transformation of sorghum and selection for resistance to the herbicide phosphinotricin conferred by the selectable marker, bar, in the transformation vector (Dellaporta, personal communication 2017). The results from the current study involve analysis of $\mathrm{T}_{1}$ plants produced from the $\mathrm{T}_{0}$ events. Some of these plants showed resistance to the herbicide, and the presence of the transgene was confirmed by PCR and Southern blots compared with the segregating wild-type plants. Analysis using confocal microscopy was performed for citrine fluorescence, and seed morphology in SS and PS was examined in mature inflorescences.

\section{Methods}

Agrobacterium-mediated transformation

Agrobacterium-mediated transformation of sorghum cv BTx430 was performed following the method described in chapter 2 of this thesis (see also, NelsonVasilchik et al. 2018; Do et al. 2018) using the same construct described by Hayward et al. (2016) (pYU2996 SK1 $\Delta$ SVL:Citrine:SVL; see Figure 4). The resulting 
transgenic plants were then eventually transferred to Plant Cons, and finally to soil (Metro-mix). The transformation experiments were performed by Kimberly NelsonVasilchik and the resulting transgenic plants were made available for this study. Paint Assay

The To plants were swabbed with $3 \%$ bialaphos (referred to as the 'paint assay') to evaluate the presence and active expression of the bar gene. The 'paint assay' is non-destructive and allows for accurate diagnosis of resistant and sensitive plants. Wild type BTx430 plants were used as controls. Transgenic $\mathrm{T}_{1}$ individuals were also confirmed for phenotypic resistance on the swabbed region indicating the presence and active expression of the bar gene.

Genomic DNA extraction

Genomic DNA was extracted from $T_{1}$ plants (Chen and Dellaporta 1994). Leaf tissue was collected from $\mathrm{T}_{1}$ plants, then ground with a mortar and pestle to a fine powder in liquid nitrogen. The plant tissue powder was then incubated with lysis buffer UEB3 (mixed by Urea, Tris, EDTA, Na2SO4, N-laurylsarcosine and PVP) to break down the cellular membranes. Those samples were extracted with phenol:chloroform and centrifuged to precipitate most of the extracted plant material. The resulting suspension solution was centrifuged with isopropanol to precipitate DNA pellet. The DNA pellet would be dissolved by TE, Acetate and Qiagen RNase, Qiagen RNase was used to remove the RNA from DNA. The dissolved DNA solution was centrifuged with phenol:chloroform to precipitate rest waste from previous steps, the upper suspension from centrifuged tube contain most DNA materials and was centrifuged with isopropanol to form the DNA pellet. The collected DNA pellets were 
dissolved by TE, then purified with $95 \%$ ethanol and $2.5 \mathrm{M}$ ammonium acetate. Purified DNA samples were rinsed by $70 \%$ ethanol and prepared for PCR and Southern blots.

PCR

The polymerase chain reaction (PCR) was used to determine the presence of bar and citrine cassettes in $\mathrm{T}_{1}$ plants. The PCR reactions were performed with the KAPABIOSYSTEMS KAPA3G Plant PCR kit. Primer information for the two genes is given in the Appendices (Table $2 \mathrm{a}, \mathrm{b}$ ). Because the Tm for two gene primers is $60.0 \mathrm{oC}$ and the product size is approximately $500 \mathrm{bp}$ each for the bar and citrine cassettes, the chosen annealing temperature was $55_{\circ} \mathrm{C}$ with a 30 second elongation time for 35 cycles in the thermocycler program.

Southern blot

Southern blots were used to determine approximate insert copy number. The Southern blots were performed with the Roche DIG Southern blot kit and the bar primer was used to produce the DIG-labeled probe for the hybridization step. The Southern blot protocol was performed according to the instructions in the Roche DIG Southern blot kit. The extracted genomic DNA was digested by restriction enzyme HindIII-HF (New England BioLabs). There no HindIII digestion sites in the complete bar gene sequence. Therefore, a positive band on blot membrane represents a complete, intact bar gene copy. Therefore, the number of bands on a given blot sample indicates the gene copy number for the gene. The digestion procedure was set up in 37. $\mathrm{C}$ water bath for 16 hours. The digested genomic DNA would be separated to different sequence size by gel electrophoresis. Then, the separated and digested 
genomic DNA would be transferred from gel to blot membrane. The blot membrane would be hybridized with bar probe in DIG easy hybridization solution at 65 。 $\mathrm{C}$ for 16 hours. The hybridized blot membrane needed to be washed to remove undesired probe by using stringency buffer, and let bar probe connecting to antibody in block solution with Anti-DIG-AP. Then, the blot membrane would be covered with chemiluminescent CSPD solution and exposed to Lumi-Film. The hybridization result on the blot membrane would be revealed on the Lumi-Film.

Confocal microscopy

Citrine was imaged using water immersion confocal microscopy according to established protocols (Hayward et al. 2016). This work was done at the Leduc Bioimaging Facility in Brown University. Because citrine is fused with $s k l$ in the pYU2996 SK1 $\triangle$ SVL:Citrine:SVL construct used in this study (Figure 4), the expression of Citrine also indicates the co-expression of SK1.

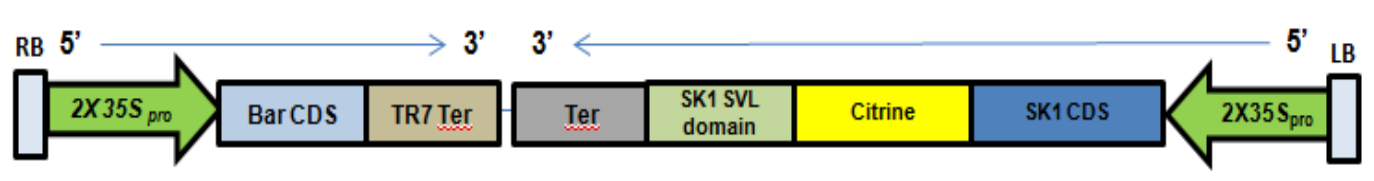

Figure 4. The $s k 1$ transgene (pYU2996 SK1 $\Delta$ SVL:Citrine:SVL) construct (Hayward et al. 2016). From T-DNA right border (RB) at left and 5' to 3', the constitutively expressed double $35 \mathrm{~S}$ promoter (green) from cauliflower mosaic virus (CaMV) is used to drive expression of the bar CDS (coding sequence) selectable marker (light blue) fused to the TR7 terminator (brown). From the T-DNA left border (LB) at right and 5' to 3', the constitutively expressed double 35S promoter (green) is again used to drive expression of the silkless 1 coding sequence SK1CDS (dark blue) fused directly to the coding sequence for citrine (yellow) and the SK1 SVL domain for peroxisomal targeting (pale green) and the $35 \mathrm{~S}$ termination signal $\operatorname{Ter}$ (grey). 


\section{Results}

Transformed To sorghum plants were produced using Agrobacterium harboring the pYU2996 SK1 $\Delta$ SVL:Citrine:SVL construct (Figure 4) for transformation in the sorghum variety BTx430. The To plants were selfed to produce a segregating population of $\mathrm{T}_{1}$ seeds which were used for further characterization. Seeds were harvested at maturity and stored at $25 \mathrm{o}$ in darkness.

The T1 seeds harvested from pYU2996 Event \#1, plant \#1, were used to grow 25 segregating plants. Three plants $(\# 10, \# 11, \# 21)$ of the 25 plants showed sensitivity to bialaphos by the 'paint assay' indicating segregation of the bar gene in the $\mathrm{T}_{1}$ population. The remaining plants showed resistance to bialaphos in the 'paint assay'.

Thirteen plants were chosen at random for further characterization (Figures 5, 6, 7 and 8). The lines \#1,\#2, \#3,\#4,\#6, \#7, \#9, \#11, and \#13 showed resistance to bialaphos in the 'paint assay' (Figure 5), confirming the presence and active expression of the bar gene. The lines \#5, \#8, \#10 and \#12 were sensitive to bialaphos indicating segregation of the transgene in the $\mathrm{T}_{1}$ generation.

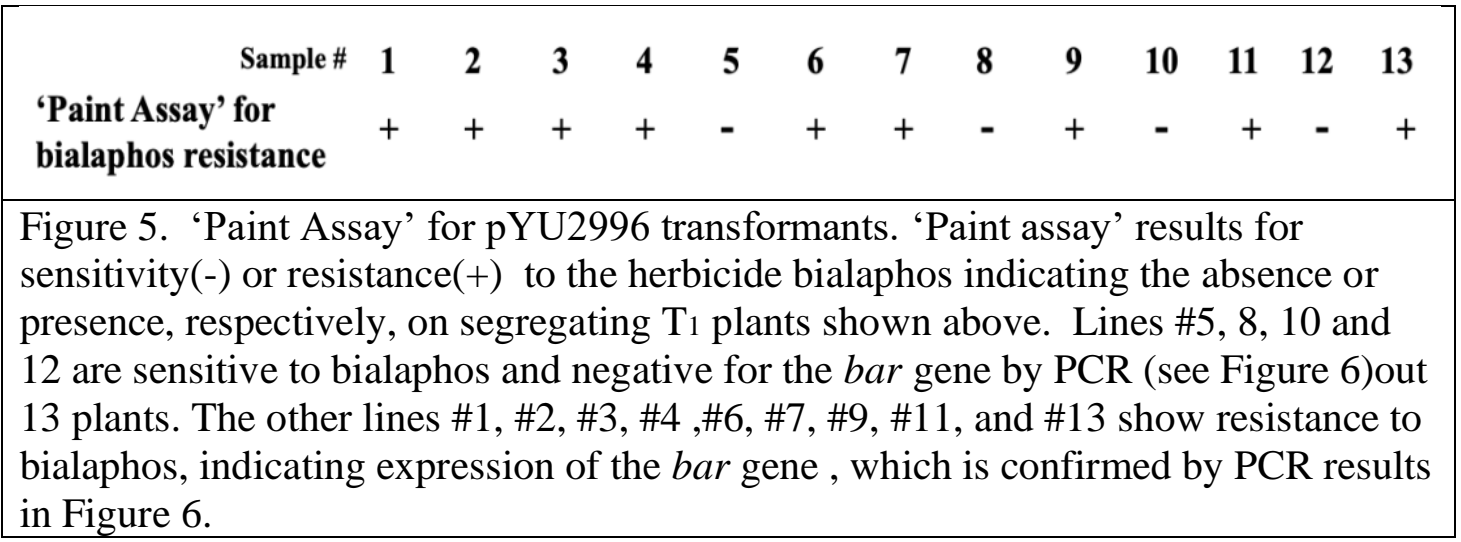

Molecular characterizations were performed using PCR for bar and citrine (Figures 6 and 7, respectively) analysis. PCR analysis was conducted for all T1 plants 
in this study using bar and citrine primers (Figure 6, 7. Also see Table 2 a, b; Appendices). PCR analysis for the bar gene should result in an expected size for the product of 513 bp. Plants \#5, \#8,\#10, and \#12 are negative for the presence of the bar sequence. Plants \#1,\#2,\#3, \#4,\#6,\#7, \#9, \#11, and \#13 have positive bands with the expected molecular weight of $513 \mathrm{bp}$. The pattern of PCR results is for all samples consistent with the bialaphos 'paint assay' results shown in Figure 5. The PCR analysis of the citrine gene cassette has an expected size of $421 \mathrm{bp}$. The pattern of results is consistent with the bialaphos 'paint assay' results shown in Figure 5 and the PCR results for the bar gene shown in Figure 6 . Plants \#5, \#8, \#10, and \#12 are negative for the presence of the citrine sequence. Plants \#1, \#2, \#3, \#4, \#6, \#7, \#9, \#11, and \#13 all have positive bands.

In both PCR tests, the positive control plasmid has a strong band and nontemplate control $\mathrm{H}_{2} \mathrm{O}$ does not have any band. These results show that the PCR assay is valid and without any contamination or artifacts. Also, comparison between the PCR results for the bar gene (Figure 6) and citrine gene (Figure 7) show that plants $\# 1, \# 2, \# 3, \# 4, \# 6, \# 7, \# 9, \# 11$, and \#13 have positive bands, demonstrating the presence of both the bar and citrine genes. Plants \#5, \#8, \#10, \#12 were PCR negative for both bar and citrine genes and probably the result of segregation in the $\mathrm{T}_{1}$ generation. 


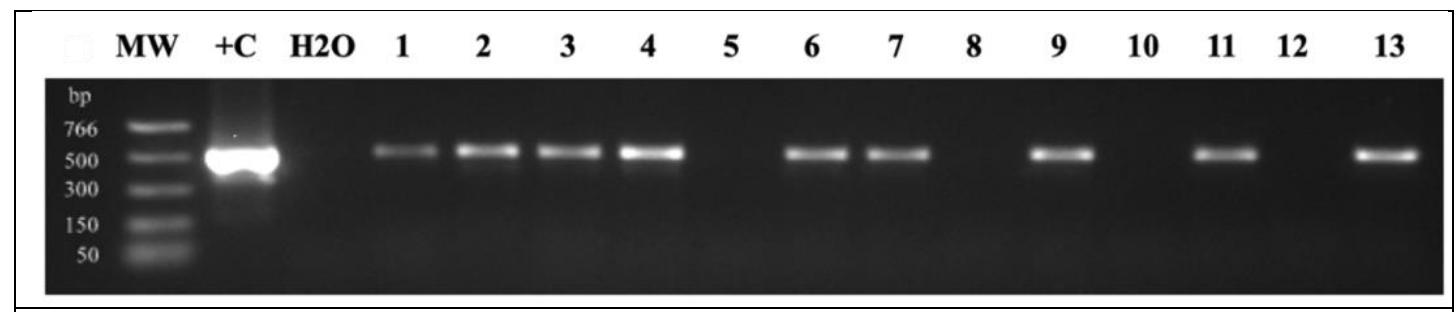

Figure 6. PCR result for the presence of the bar gene cassette. The expected product is $513 \mathrm{bp}$. The pattern of results is same with the bialaphos 'paint assay' results shown in Figure 5. Plants \#5, \#8, \#10, and \#12 are negative for the presence of the bar sequence. Plants \#1, \#2, \#3, \#4, \#6, \#7, \#9, \#11, and \#13 have positive bands. The DNA ladder serves as a PCR product size ruler. The plasmid sk1 construct as positive PCR control $(+\mathrm{C})$. The $\mathrm{H}_{2} \mathrm{O}$ lane is the non-template control to determine the presence of contamination in PCR reaction reagents.

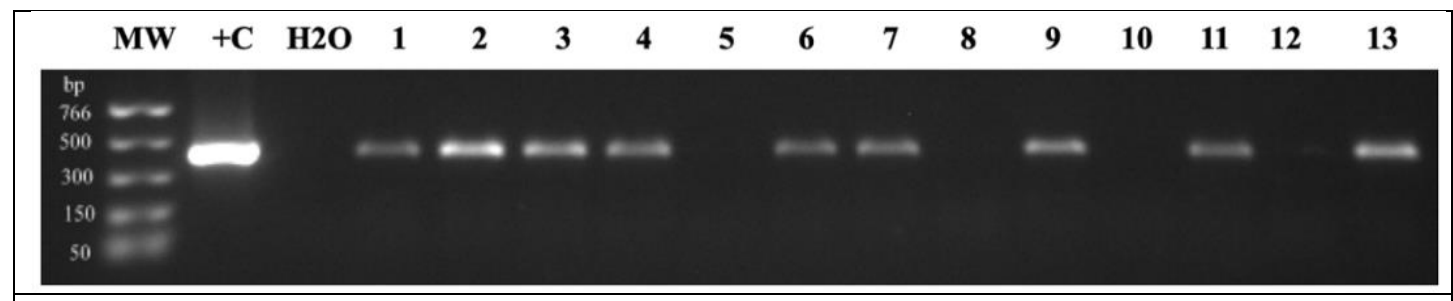

Figure 7. PCR result for the presence of the citrine gene cassette. The expected product is $421 \mathrm{bp}$. The pattern of result is same with the bialaphos 'paint assay' results shown in Figure 5 and the PCR results for the bar gene shown in Figure 6. Plants \#5, \#8,\#10, and \#12 are negative for the presence of the citrine sequence. Plants \#1, \#2, \#3, \#4,\#6, \#7, \#9, \#11, and \#13 have positive bands. The DNA ladder serves as a PCR product size ruler. The plasmid $s k l$ construct as positive PCR control $(+\mathrm{C})$. The $\mathrm{H}_{2} \mathrm{O}$ lane is the non-template control to determine the presence of contamination in PCR reaction reagents.

Southern blots and expression of the citrine CDS further confirm the integration of the T-DNA cassettes (Figures 8 and 10, respectively). Southern blots were conducted to re-confirm the presence of the transgene and also to determine the transgene copy number in $\mathrm{T}_{1}$ plants. The bar primer (See Table $2 \mathrm{a}, \mathrm{b}$; Appendices) was used to produce probe, so the bar sequence on the membrane would be targeted during the hybridization to determine integration of the transgene. As previously shown by the 'paint assay' results and the PCR analyses, plants \#5, \#8, \#10, and \#12 are negative for the presence of the bar sequence and plants \#1, \#2, \#3, \#4 ,\#6, \#7, \#9, 
$\# 11$, and \#13 have positive bands. All positive samples show the single bar gene copy insert in the blot result. Therefore, the $\mathrm{T}_{1}$ transgenic plants have a single SK1 $\triangle$ SVL:Citrine:SVL construct copy. This result rules out the possibility of anomalous expression of the transgene which is often observed in transgenic plants with multiple gene copies. The black exposed dots in this blot are unexpected background but do not weaken interpretation of the positive results.

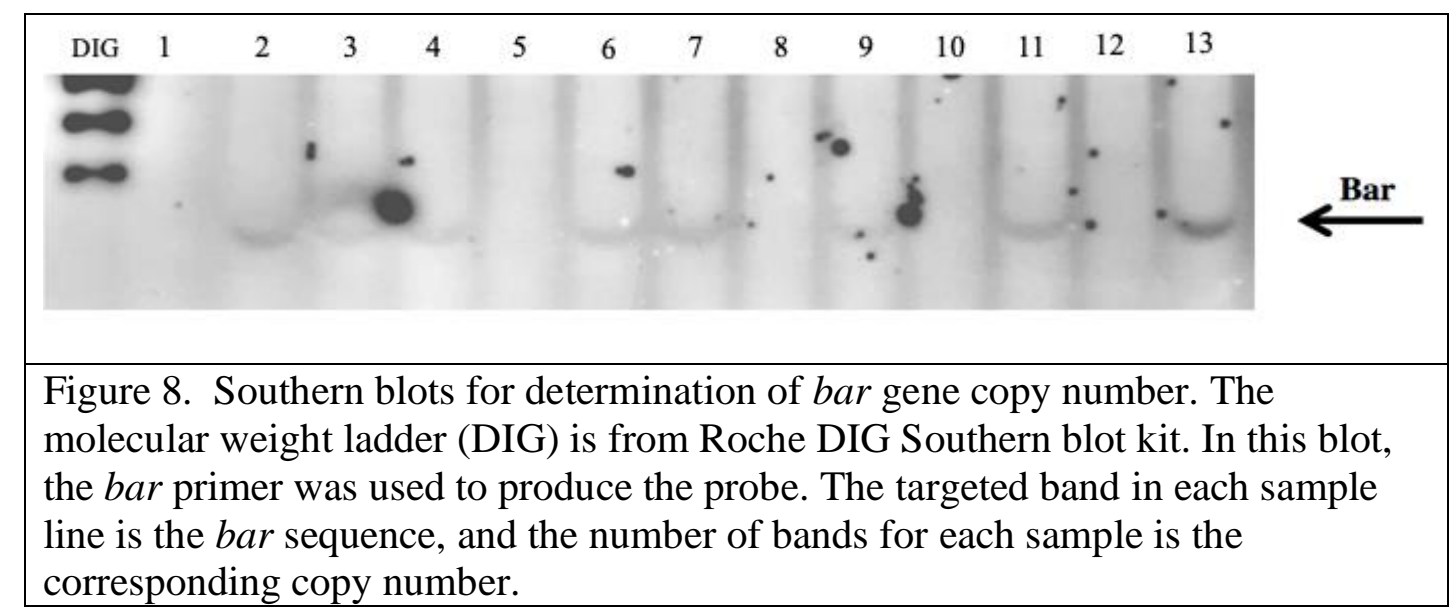

A Zeiss water immersion confocal microscope was used to determine the expression of citrine in $\mathrm{T}_{1}$ plants (Figures 9 and 10). E. coli expressing citrine and non-transformed E. coli were used as controls for confocal microscope imaging shown in Figure 9. 


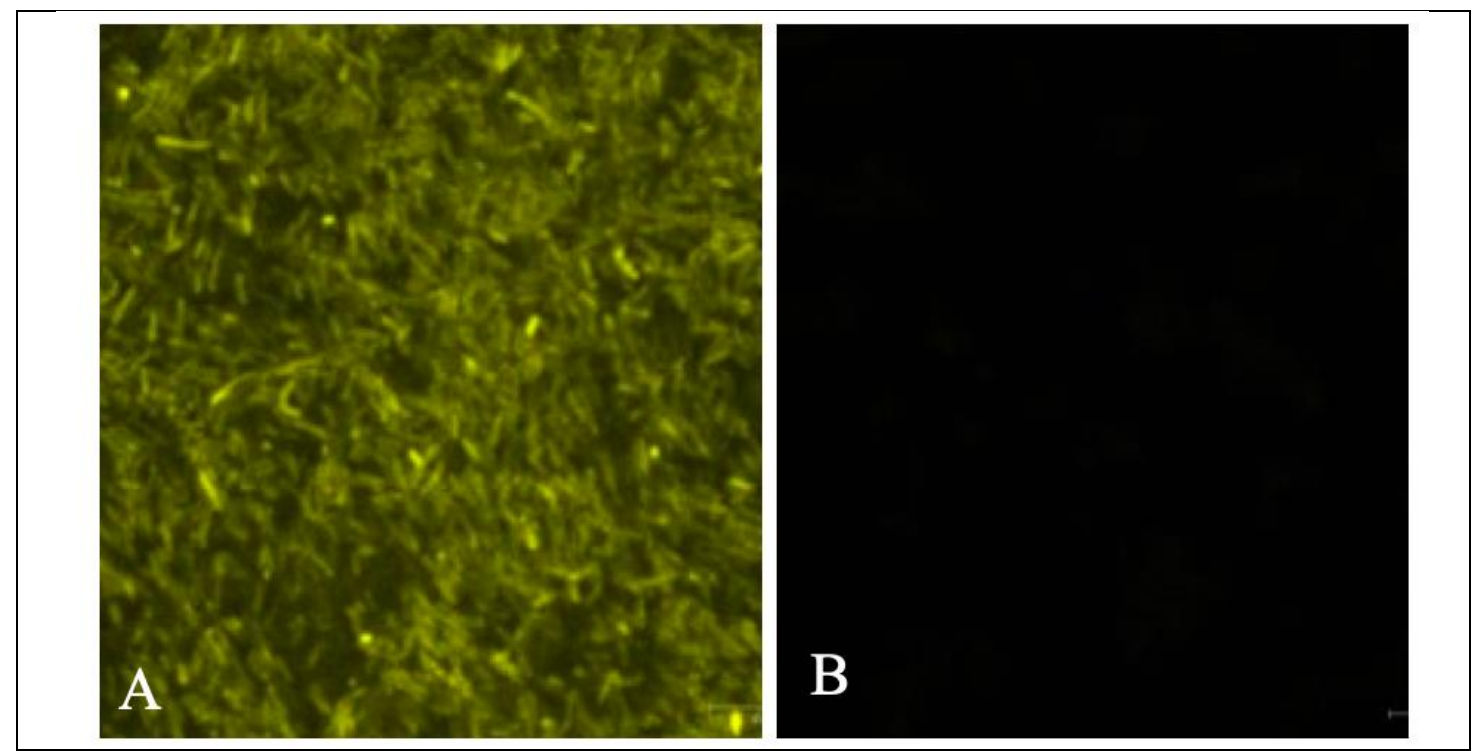

Figure 9. Confocal images of E. coli expressing citrine (A) and E. coli negative control (B)

A: Citrine is expressed in E. coli serving as a convenient positive control for imaging citrine in the confocal microscope. B: The E. coli without expressing Citrine served as negative control, it does not have any yellow fluorescence.

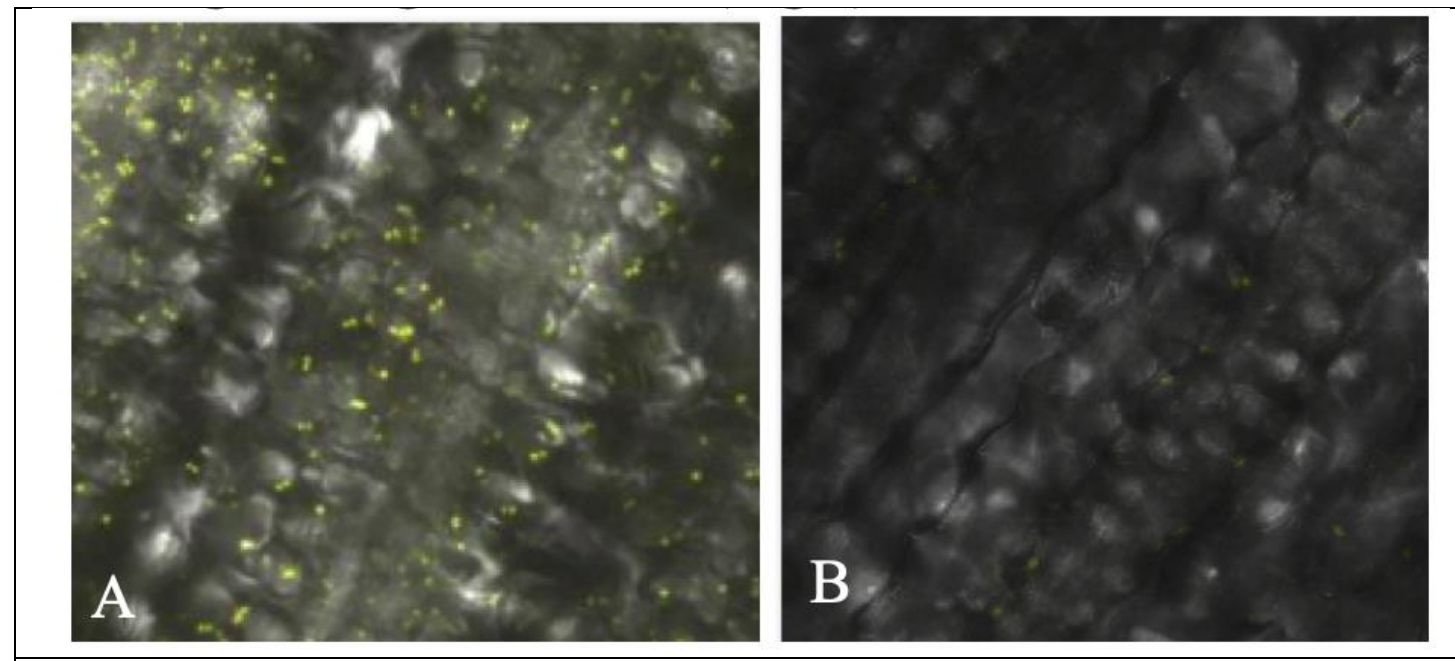

Figure 10. Confocal images of sorghum expressing citrine (A) and sorghum negative control (B) Confocal images of PCR positive (A) and PCR negative plants (B) from a segregating population in etiolated leaves show citrine positive structures consistent with the size of peroxisomes. Note that the negative control however does show some background autofluorescence.

Figure 9A shows E. coli expressing citrine and Figure 9B shows the nontransformed E. coli negative control. These results confirm that the confocal microscope is capable of detecting citrine expression. Young leaves were collected 
from etiolated plants that were PCR positive for citrine and negative control plants. The citrine PCR positive leaves show citrine positive structures consistent with the size of peroxisomes (Figure 10A) The PCR negative samples also show some yellow fluorescence in background (Figure 10B), which may be autofluorescence. However, clearly these samples show stark differences. These putative results therefore need further investigation, but indicate that the citrine cassette is being expressed in plants positive for the presence of the transgene.

The presence of the transgene was confirmed in all PCR positive plants. However, there were no phenotypic differences between PCR positive and negative plants when their inflorescences were compared (Figure 11). The PS were aborted in PCR positive inflorescences (Figure 11A-D), and the SS had mature fruits. This phenotypic result of PCR positive (Figure 11A-D) is almost the same compared with PCR negative plants (Figure 11E-H). When the whole size of the PCR positive inflorescence (Figure 12A) was compared to the PCR negative (Figure 12B) equivalent, there was no obvious phenotypic differences between their morphological architecture. The positive plants do not exhibit a protected phenotype for the pedicellate flower, and both have approximately the same number of seeds. These results indicate that the same construct used in maize (Hayward et al. 2016) does not confer a phenotype in sorghum. 

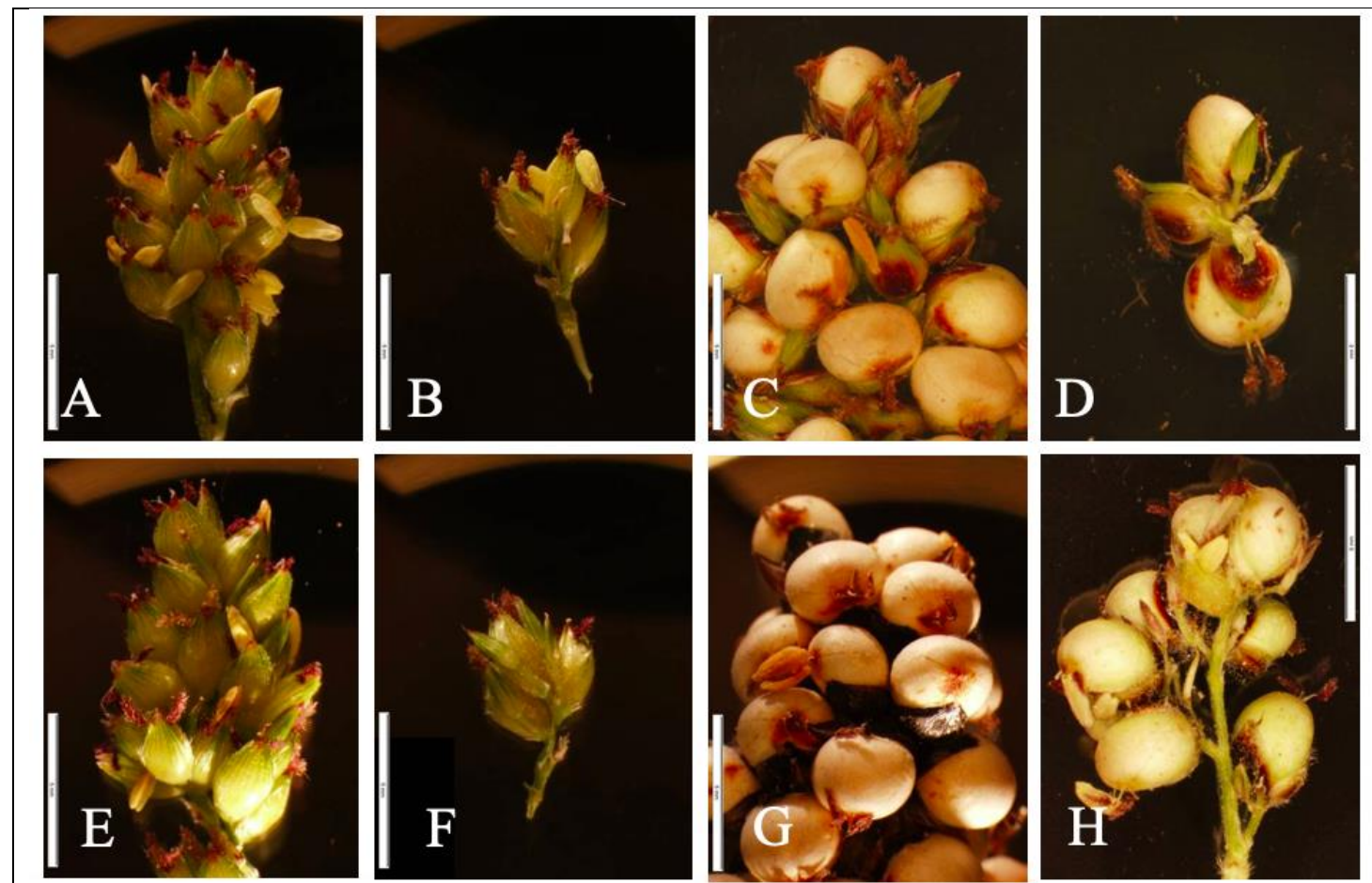

Figure 11. Dissecting light scope images of pYU2996 SK1 $\Delta$ SVL:Citrine:SVL PCR positive inflorescence (Top row) and negative control (Bottom row). Developmental floral morphology of PCR positive plants (A-D) compared with PCR negative plants $(\mathrm{E}-\mathrm{H})$ show no phenotypic differences in the development of the pedicellate (PS) or sessile (SS) flowers, and are equivalent to those of non-transgenic plants. 


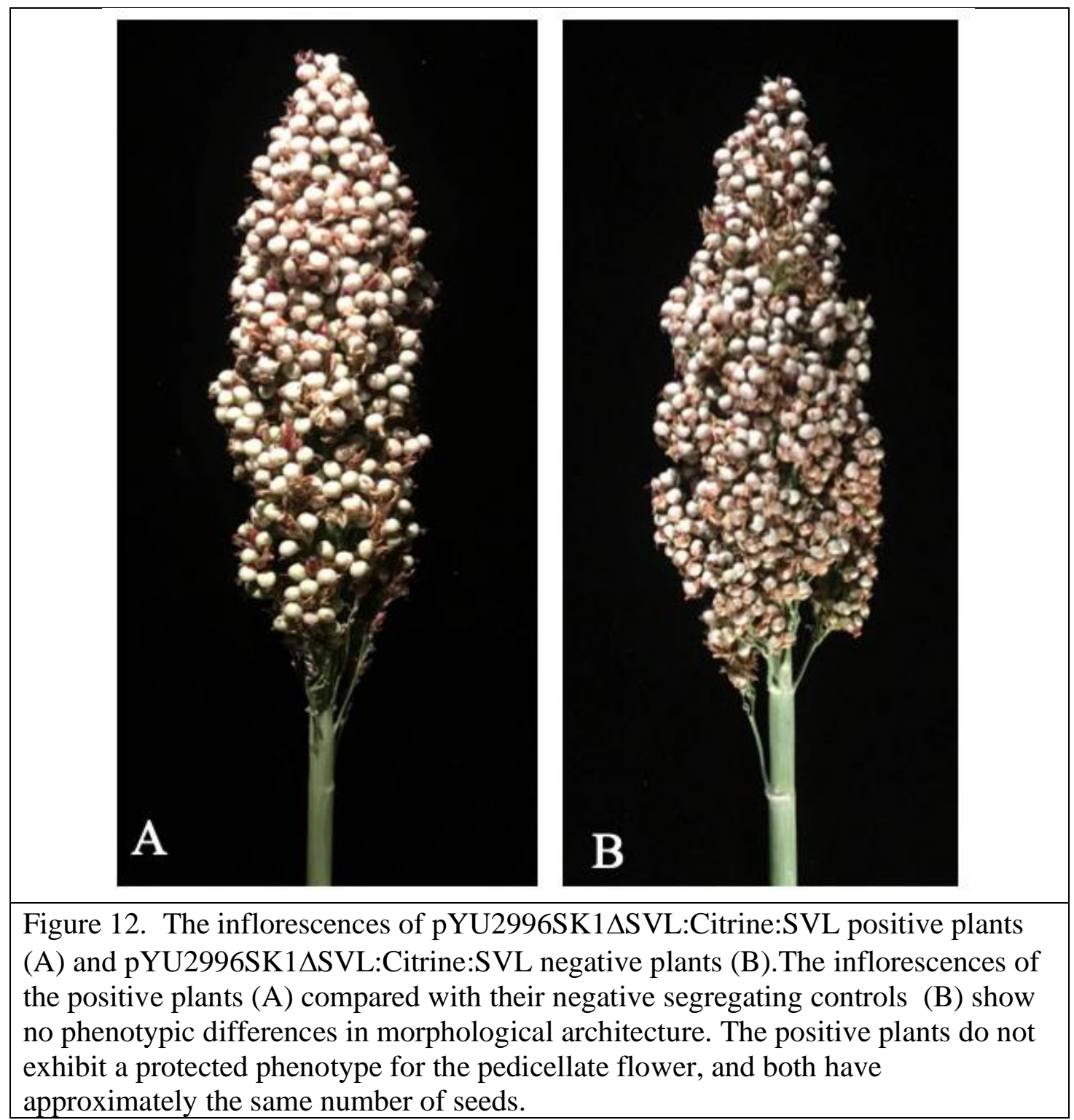

\section{Discussion}

Phenotypic analysis (paint assay) and genotypic analysis confirmed the presence of the Hayward et al. (2016) construct in $\mathrm{T}_{1}$ transgenic sorghum plants. After the pYU2996SK1 $\Delta$ SVL:Citrine:SVL constructs integrated into the sorghum genome it conferred bialaphos resistance from the constitutively expressed bar gene. Therefore, the plants showing sensitive results by the 'paint assay' indicates that these plants are not expressing the bar gene and are likely non-transgenic, and lacking the T-DNA 
insert after $\mathrm{T}_{1}$ segregation. The resistant plants indicate that they are transgenic sorghum lines with at least one functional bar gene. The PCR bar and citrine positive $\mathrm{T}_{1}$ plants further confirmed the 'paint assay' results. The single copy number of $s k 1$ construct in $\mathrm{T}_{1}$ plants was confirmed by southern blot analysis. The expression of citrine was detected via confocal microscope, and the PCR positive $\mathrm{T}_{1}$ plants do express strong fluorescence. Since the $s k l$ is fused with citrine (Figure 4), the expression of citrine in the PCR positive $\mathrm{T}_{1}$ plants also indirectly indicated the expression of $s k 1$. All of these tests indicated the presence and expression of the pYU2996SK1 $\Delta$ SVL:Citrine:SVL construct. The $s k 1$ construct was hypothesized to protect the pedicellate flower via promoting the expression of $s k 1$ in sorghum. The overexpression of the maize $s k l$ construct did protect the female primordia in maize, but it had no apparent impact on the protection of the pedicellate flower in sorghum. The PS were still aborted in PCR positive plants, and were phenotypically identical to the PCR negative plants. There are several possible explanations for the observed results. First, maize is monecious; its floral development is different with sorghum. The maize genome is highly homologous with sorghum, but the maize skl gene product may not function in the sorghum jasmonic acid pathway. In addition the $s k 1$ orthologue in sorghum is only $72 \%$ homologous to the maize $s k 1$ gene at the protein level. However, similar experiments with constructs from other plants used in transgenic experiments, even from distantly related plants, have been successful (Kausch and Altpter, personal communication) in conferring the expected phenotype. Therefore, constitutive overexpression of maize $s k 1$ may not be able to protect the pedicellate flower in sorghum transformed with the pYU2996SK1 $\Delta$ SVL:Citrine:SVL 
construct. Secondly, even though the corresponding genotypic and phenotypic analysis had confirmed the presence and expression of the maize $s k l$ construct in transformed sorghum, the expression level of $s k l$ could be insufficient to protect the pedicellate flower. Third, the sorghum variety used in this project was cv BTx430, and the expected phenotype may require a different sorghum line having the appropriate genetic background.

In conclusion, the desired transgenic lines containing a heritable and functional version of maize $s k l$ were successfully produced and analyzed. The maize $s k l$ may not be able to protect pedicellate flowers in sorghum based on the above described possibilities. However, all of the $\mathrm{T}_{1}$ plants were cultivated from single transgenic event \#1. The possibility exists that the inserted $s k l$ construct may be not complete and identical to the original construct because of some occasional insertions or deletions within the $s k 1$ construct. This possibility could explain the inability of the inserted construct to produce the expected phenotype. In the follow-up work, similar analyses as applied in this current study may need to be done on $\mathrm{T}_{1}$ plants from different transgenic events. Also, western blots could be used to further confirm definitively the expression of $s k 1$. Future studies should also focus on the use of genome editing to create knockouts not only of $s k l$ but other candidate genes such as the sorghum $m s d l$ gene. 


\section{CHAPTER 2: THE DEVELOPMENT OF TRANSGENIC SORGHUM WITH CAS9}




\section{Chapter 2: The Development of Transgenic Sorghum with Cas9}

\section{Introduction}

Sorghum (Sorghum bicolor) represents the third largest cereal crop in the world and the fifth largest in the US (Belide et al. 2017; Jiao et al. 2018). The sorghum grain is widely used for food, animal fodder and biofuels (Jiao et al. 2018). Any agronomic improvements for sorghum will contribute toward enhancing the value of this important crop. Modern approaches to enhance traditional breeding and selection strategies, including genetic transformation strategies and associated genome editing approaches, are necessary and important tools to contribute toward these

improvements. Recently, a new gene editing tool has been developed, which is termed Clustered Regularly Interspaced Short Palindromic Repeats (CRISPR) along with CRISPR-associated proteins. The modified CRISPR/Cas9 system is much simpler to design than previous genome editing approaches such as Transcription Activator-Like Endonucleases (TALENs) or Zinc Finger Nucleases (ZFNs). It is easier to construct CRISPR vectors than was previously possible because CRISPR relies on precise nucleotide base pairs in contrast to the less precise protein binding domains of TALENs and ZFNs. The induced sgRNA and Cas9 protein can make multiple doublestranded breaks simultaneously, resulting in enhanced mutagenesis and gene editing. The CRISPR/Cas9 system has been applied in several plant genome editing projects to date (Bortesi and Fischer 2015; Kausch et al. 2019). For example, a nicotine-free and nontransgenic tobacco has been developed via CRISPR/Cas9 editing (Schachtsiek and Stehle 2019). 
In the project described here, transgenic sorghum lines were developed to constitutively express bar, gfp and TaCas9. This stable transgenic line would provide a valuable tool for future genome editing projects in sorghum since only the guide RNAs would need to be introduced. The development of transgenic sorghum lines with constitutively expressing TaCas 9 would be an important tool for producing other improvements of sorghum through targeted genetic modification. This project focuses on the generation and molecular characterization of the transgenic events for the TaCas 9 containing construct. The long term goal of this project is to verify the efficiency of stable Cas9 expression for generating edited events in future transgenic sorghum lines.

Two gene constructs are involved in this project and made by the Voytas lab at the University of Minnesota: pNG111-ZmUbi::TaCas9_PvUbi::1GFP; and pNG108PvUbi::1GFP [See Appendices Figure 1 and 2]. The genes in the vector for TaCas 9 in the T-DNA region are driven by the maize ubiquitin promoter to provide for constitutive expression [Figure 13 and 14]. The T-DNA in pNG111ZmUbi::TaCas9_PvUbi::1GFP is described (Figure 13). Toward the 3' end of the cassette insert, the bar gene is driven by the constitutive ubiquitin promoter, PvUbi2, from Panicum virgatum ( $\mathrm{Pv}$; switchgrass). This promoter is ligated along with the 5' untranslated region (UTR) and the PvUbi2 intron1 to the bar gene and the CMV 35S termination sequence as the selectable marker. This construct should constitutively express bialaphos resistance. Toward the 5' end of the cassette, the $g f p$ gene is driven by the PvUbil promoter which is fused to the 5' untranslated region and the PvUbi1 intron1. The $m G F P$ coding sequence (CDS) and the Psrbc S E9 termination sequence 
serve as a constitutively expressed visible marker. The $\operatorname{Ta} \operatorname{Cas} 9$ cassette is inserted between the bar and $g f p$ cassettes and consists of the maize $(\mathrm{Zm})$ ubiquitin promoter fused to the 5' UTR and the ZmUbil intronl ligated to the TaCas9 CDS gene and the heat shock protein (HSP) termination sequence. This cassette to be designed to constitutively drive $\operatorname{Ta} C a s 9$ expression. This entire, intact construct should constitutively express bar, gfp, and TaCas9. The pNG111vector has the TaCas 9 region, which is required to evaluate the efficiency of stably expressed TaCas9. The pNG108 vector serves as a control, lacking the $\operatorname{TaCas} 9$ construct. Both vectors contain both bar and $g f p$ also driven by a constitutive promoter, namely the Ubiquitin promoter from switchgrass (Panicum virgatum). The selectable marker in both constructs, pNG111and pNG108, is the bar gene conferring resistance to the herbicide bialaphos. The expression of $g f p$ is used as a visible marker to detect the presence of the cassette. The pNG108 has the bar and $g f p$ region without the $\operatorname{TaCas} 9$ sequence, and serves as negative control for pNG111. The same cassettes for $\mathrm{pNG111}$ is described (Figure 13). Both bar and $g f p$ expression were used in pNG108. Once the stable transgenic sorghum lines are developed and characterized containing both constructs, the designed guide RNAs will then be delivered into plants via particle bombardment and tested in future experiments. The efficiency of editing can be evaluated and quantified based on the degree of gene modification success by CRISPR/Cas9. 


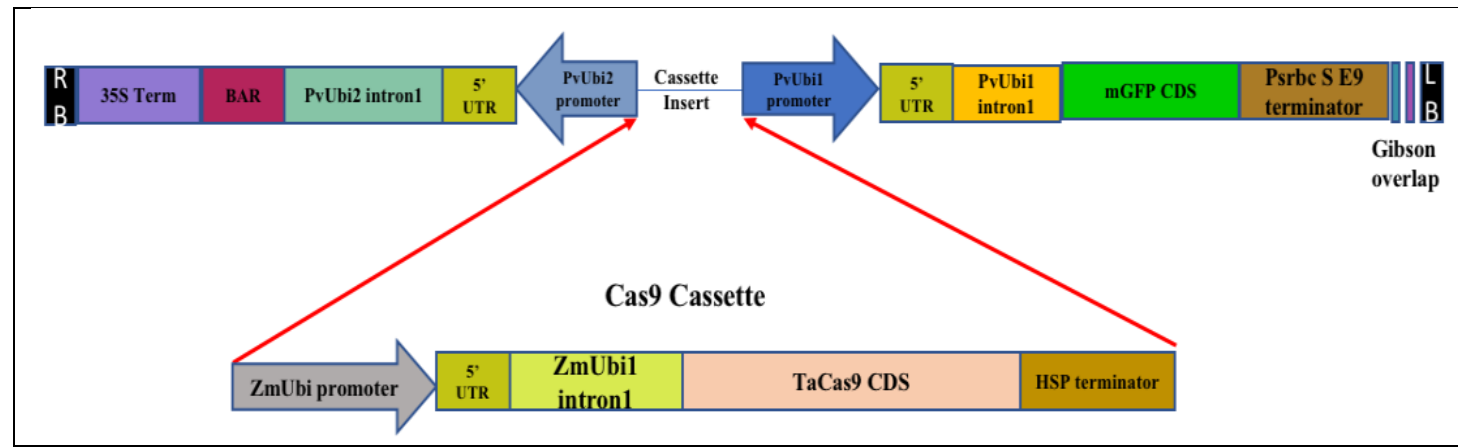

Figure 13. T-DNA in pNG111-ZmUbi::TaCas9_PvUbi::1GFP. To the left of the cassette insert, the bar gene is driven by the constitutive ubiquitin promoter from Panicum virgatum ( $\mathrm{Pv}$; switchgrass) PvUbi2 (pale blue arrow) which is fused to the 5' untranslated region (UTR in dark yellow), and the PvUbi2 intron1 (pale green) ligated to the bar gene (BAR in maroon) and the CMV 35S Termination sequence (in purple) as the selectable marker. To the right, the $g f p$ gene is driven by the PvUbil promoter (deep blue arrow), which is fused to the 5' untranslated region (UTR in dark yellow), and the PvUbil intron1 (orange) ligated to the $m G F P$ coding sequence (CDS) gene (mGFP CDS in green ) and the Psrbc S E9 Termination sequence (in brown) as a visible marker. The $\operatorname{Ta} \operatorname{Cas} 9$ cassette is inserted between the bar and $g f p$ cassettes and consists of the maize ubiquitin promoter ( $\mathrm{ZmUbi}$ in grey) which is fused to the 5' untranslated region (UTR in dark yellow), and the ZmUbi1 intron1 (pale yellow) ligated to the TaCas $9 C D S$ gene (in pale orange) and the heat shock protein (HSP) Termination sequence (in brown) to code for the which encodes the Cas 9 protein. This construct should constitutively express bar, $g f p$, and TaCas 9 .

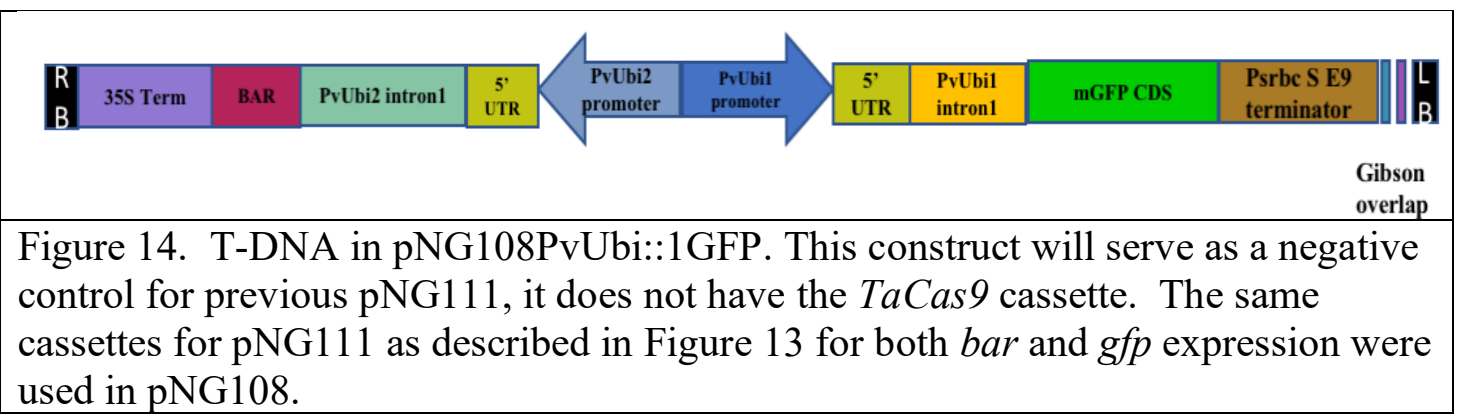

\section{Methods}

Agrobacterium-mediated transformation

Standard Agrobacterium-mediated transformation of sorghum cv BTx430 was conducted using immature embryos 12-14 days post-pollination as explants. The standard protocols for sorghum transformation were followed (Nelson-Vasilchik et al. 
2018; Do et al. 2018). The specific media specifications are shown in the Appendices (Table 1). The plasmids for pNG111 and pNG108 were independently isolated from their E.coli cloning vectors and transferred to the Agrobacterium strain AGL1 for sorghum transformation. Transformed AGL1 colonies were selected on YEP agar plate with antibiotic kanamycin and rifampicin, and grown following standard protocols (Nelson-Vasilchik et al. 2018). The isolated colonies were used to grow overnight cultures which were inoculated into infection media for transformation. These cultures were used to inoculate wild type sorghum cv BTx430 immature embryos which are oriented abaxial side up. Incubation with Agrobacterium harboring either pNG111 or pNG108 was for 3 days at 28 o $\mathrm{C}$ in the dark. These embryos were then transferred to resting medium for 14 days, lacking the herbicide bialaphos as the selective agent for the presence of the bar gene. Prior to selection, this medium promotes development of somatic embryos, an essential central criterion for successful transformation in sorghum (Kausch et al. 2019). The transferred embryos were selected from non-transgenic cells on bialaphos selection medium. The resistant callus would subsequently be transferred to media to promote somatic embryo germination and then shoot growth and eventually transferred to rooting medium. These plants were then finally transferred to Plant Cons, and finally to a soil medium (Metro-mix). Paint Assay

A 'paint assay' was performed on the To plants as described in Chapter 1 of this thesis to evaluate the presence and expression of the bar gene. The 'paint assay' is non-destructive and allows accurate identification of resistant and sensitive plants. Wild type BTx430 plants were used as controls. Transgenic To individuals would 
show phenotypic resistance on the swabbed region indicating bar gene expression. The regenerated plants were grown to maturity in the greenhouse and selfed in order to recover $\mathrm{T}_{1}$ seed.

Genomic DNA extraction

DNA was isolated from To plants for the molecular analysis and transgene presence confirmation (Chen and Dellaporta 1994). Leaf tissue was collected from $\mathrm{T}_{0}$ plants. Purified DNA samples were prepared for PCR and Southern blots. PCR

The polymerase chain reaction (PCR) was used to determine the presence of bar, gfp, and TaCas 9 cassettes in To plants using protocols described in Chapter 1 of this thesis. The primer information for the three genes in pNG111 is shown in the Appendices (Table 2; a, c, d). The primers for the bar and gfp genes in pNG108 are the same as those used for $\mathrm{pNG} 111$. Because the Tm for all three primers is approximately $60.0_{\mathrm{o}} \mathrm{C}$ and their product sizes are shorter in the range of approximately $500 \mathrm{bp}$, a 55。 C degree annealing temperature was used with a 30 second elongation time for 35 cycles for the thermocycler program.

Southern blot

Southern blot analysis on To plants was performed as described in chapter 1 of this thesis. The bar primers were used to produce the DIG- labeled probe for the hybridization step.

GFP Microscopy 
GFP expression was evaluated on a Zeiss Discovery v20 microscope with the magnification 10-409 and mGFP 470 filters to detect the GFP expression in the $\mathrm{T}_{0}$ plants. Wild type sorghum served as negative control.

\section{Results}

Multiple To transgenic events for the two constructs, pNG111 and pNG108, were produced and successfully grown to maturity to yield T1 seed. As Table 1 shows, pNG111 produced 6 independent events with a total 32 plants, and pNG108 produced 1 event with a total 7 plants. Transformation experiments with pNG108 that are still in progress to generate additional independent events.

The process of stable plant transformation for sorghum requires significant experience especially with the tissue culture steps. As shown (Figure 15), colonies of resistant calli were recovered and often showed recalcitrance during the plant regeneration steps (see Table 1). All experiments with pNG111 and pNG108 were conducted using bialaphos as a selection agent for the bar gene selectable marker (see Table 1 in Appendices). Molecular analysis (described below) revealed that there were no 'escapes' in these experiments. Escapes would be putative transformants which do not test positive for the bar gene. Developing transgenic calli grew well under selection but often showed a decline on regeneration medium. The transformed pNG108 calli were developing well-formed somatic embryos on regeneration medium (Figure $15 \mathrm{~A})$. 


\begin{tabular}{|c|c|c|c|c|c|}
\hline Variety & Construct & \# of Events & $\begin{array}{c}\text { Total transgenic } \\
\text { plants }\end{array}$ & $\begin{array}{c}\text { \# of } \\
\text { Embryos }\end{array}$ & Frequency \\
\hline $\begin{array}{c}\text { BTx } \\
430\end{array}$ & pNG111 & 6 & 32 & 734 & $0.82 \%$ \\
\hline $\begin{array}{c}\text { BTx } \\
430\end{array}$ & pNG108 & $\begin{array}{c}\text { 1 (in } \\
\text { process) }\end{array}$ & 7 & 499 & $0.2 \%$ \\
\hline
\end{tabular}

Table 1. Sorghum transformation results with pNG111 and pNG108. The pNG111 lines have been developed and $\mathrm{T}_{1}$ plants .have been analyzed. The pNG108 lines are still in process

Transformed calli with pNG111 showed similar signs of decline on regeneration medium (Figure $15 \mathrm{~A}$ and $\mathrm{C}$ ). This is typical of sorghum transformation and does not appear to be construct-specific.

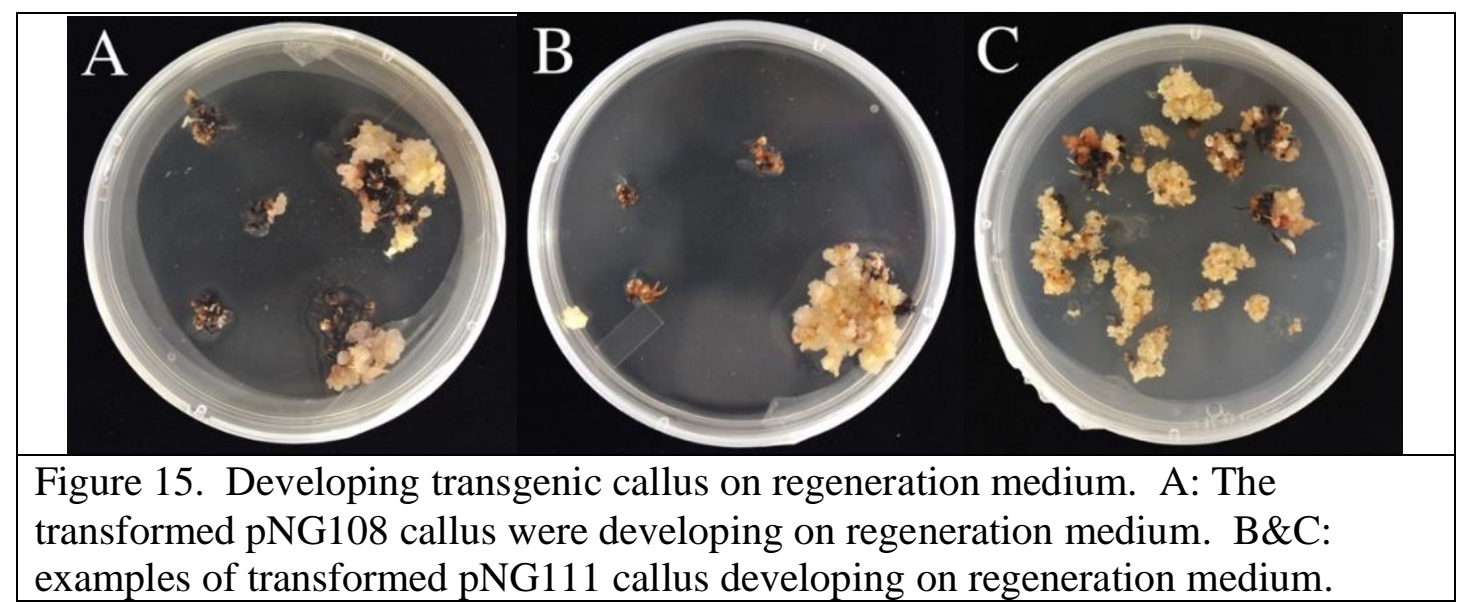

The 'paint assay' confirmed the resistance to bialaphos in all To plants. All of the plants that are bialaphos resistant reflect the expression of the bar gene in transgenic lines with no sensitive escapes (Figure 16). In general, all samples were confirmed to be transgenic, by the 'paint assay', PCR and Southern blots.

\begin{tabular}{lllllllllll|}
\hline Sample ID & $\mathbf{1}$ & $\mathbf{2}$ & $\mathbf{3}$ & $\mathbf{4}$ & $\mathbf{5}$ & $\mathbf{6}$ & $\mathbf{7}$ & $\mathbf{8}$ & $\mathbf{9}$ & $\mathbf{1 0}$ \\
\hline Bialaphos-Resistant & + & + & + & + & + & + & + & + & + & + \\
\hline $\begin{array}{l}\text { Figure 16. 'Paint assay' for pNG111\&pNG108. 'paint assay' results on } \\
\text { representative To plants transformed with the pNG11) vector and swabbed with } 3 \% \\
\text { bialaphos. }\end{array}$
\end{tabular}


PCR analysis was conducted on all To plants for the bar, gfp and TaCas9 genes (Figure 17-19). The non-template controls for all three analyses $(+\mathrm{C}$ lane in Figures 17-19) show clean results indicating that all positive bands are valid without any contamination.

PCR analysis for the bar gene cassette in To transgenic sorghum transformed with pNG111 confirmed the presence of the bar gene (Figure 17) using bar primers (see Appendices, Table 2). The expected PCR product size for bar is $513 \mathrm{bp}$. All of the tested samples were positive.

\begin{tabular}{|c|c|c|c|c|c|c|c|c|c|c|c|c|c|c|c|}
\hline & bp & MW & 1 & 2 & 3 & 4 & 5 & 6 & 7 & 8 & 9 & 10 & $+\mathrm{C}$ & $\mathrm{H}_{2} \mathrm{O}$ & MW \\
\hline Bar & $\begin{array}{l}766 \\
500 \\
300\end{array}$ & E & 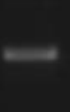 & $=$ & 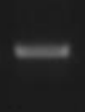 & - & $\rightarrow$ & - & - & - & - & - & - & & - \\
\hline
\end{tabular}

Figure 17. PCR analysis for the bar gene cassette in To transgenic sorghum transformed with pNG111 confirmed using bar primers (see Appendices). The expected PCR product size for bar is 513bp. DNA ladder serves as PCR product size ruler. $+\mathrm{C}$ is plasmid serves as positive control. $\mathrm{H}_{2} \mathrm{O}$ is non-template control to determine the presence of contamination in PCR reaction reagents.

These same plants were also tested for the presence of $g f p$ and $\operatorname{Ta} \operatorname{Cas} 9$ (Figure 18 and 19, respectively). The expected PCR product size for $g f p$ is $234 \mathrm{bp}$. The expected PCR product size for TaCas 9 is $363 \mathrm{bp}$. These results show that all of the pNG111 To plants exhibit the presence of bar, gfp and TaCas9 by PCR (Figure 17, 18, 19). For the pNG108 event, PCR validates the presence of both the bar and $g f p$ genes. The pattern of those PCR results are consistent with the 'paint assay' results and show the presence of the bar and $g f p$ genes and negative for TaCas 9 . 


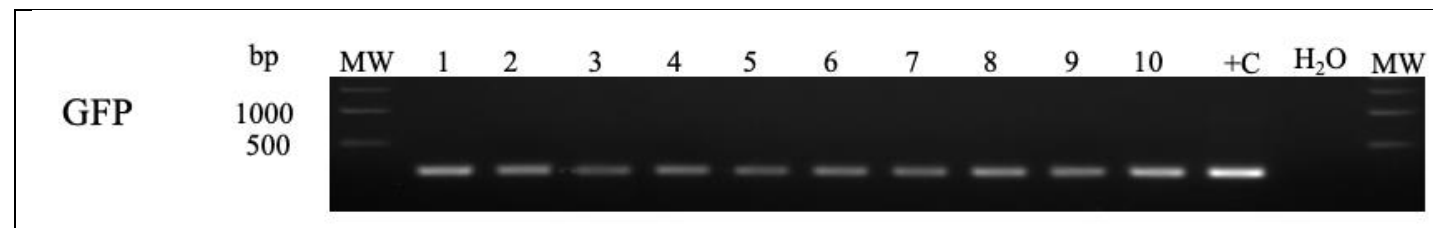

Figure 18. PCR test for $g f p$ gene cassette. The To same transgenic sorghum plants shown in Figure 17 were confirmed using the $g f p$ primer s (see Appendices). The PCR product size for $g f p$ is $234 \mathrm{bp}$. DNA ladder serves as PCR product size ruler. $+\mathrm{C}$ is plasmid to serve as positive control. $\mathrm{H}_{2} \mathrm{O}$ is non-template control to determine the presence of contamination in PCR reaction reagents.

\begin{tabular}{|llllllllllllll|}
\hline Cas9 9 & & bp & MW & 1 & 2 & 3 & 4 & 5 & 6 & 7 & 8 & 9 & 10 \\
&
\end{tabular}

The PCR results clearly show the presence of the introduced vector for all $\mathrm{T}_{0}$ plants for the bar, gfp and TaCas9 genes (Figure 17-19). Southern blot analyses were conducted on these same plants to determine transgene copy number (Figure 20). The bar primer was used to produce the probe to hybridize to the digested genomic DNA on the membrane. Samples \# 1,\#2,\#3,\#4, \#5, \#6, \#9 and \#10, all indicate single gene insertion events when probed for the bar gene. Plant \#7 and \#8 indicate multiple insertion copies, containing at least 8 bar gene copies. There is no apparent phenotypic consequences in these plants in comparison to the others or wild-type plants. Background noise, appearing as black spots are associated with these blots but do not alter or interfere with the analysis. 


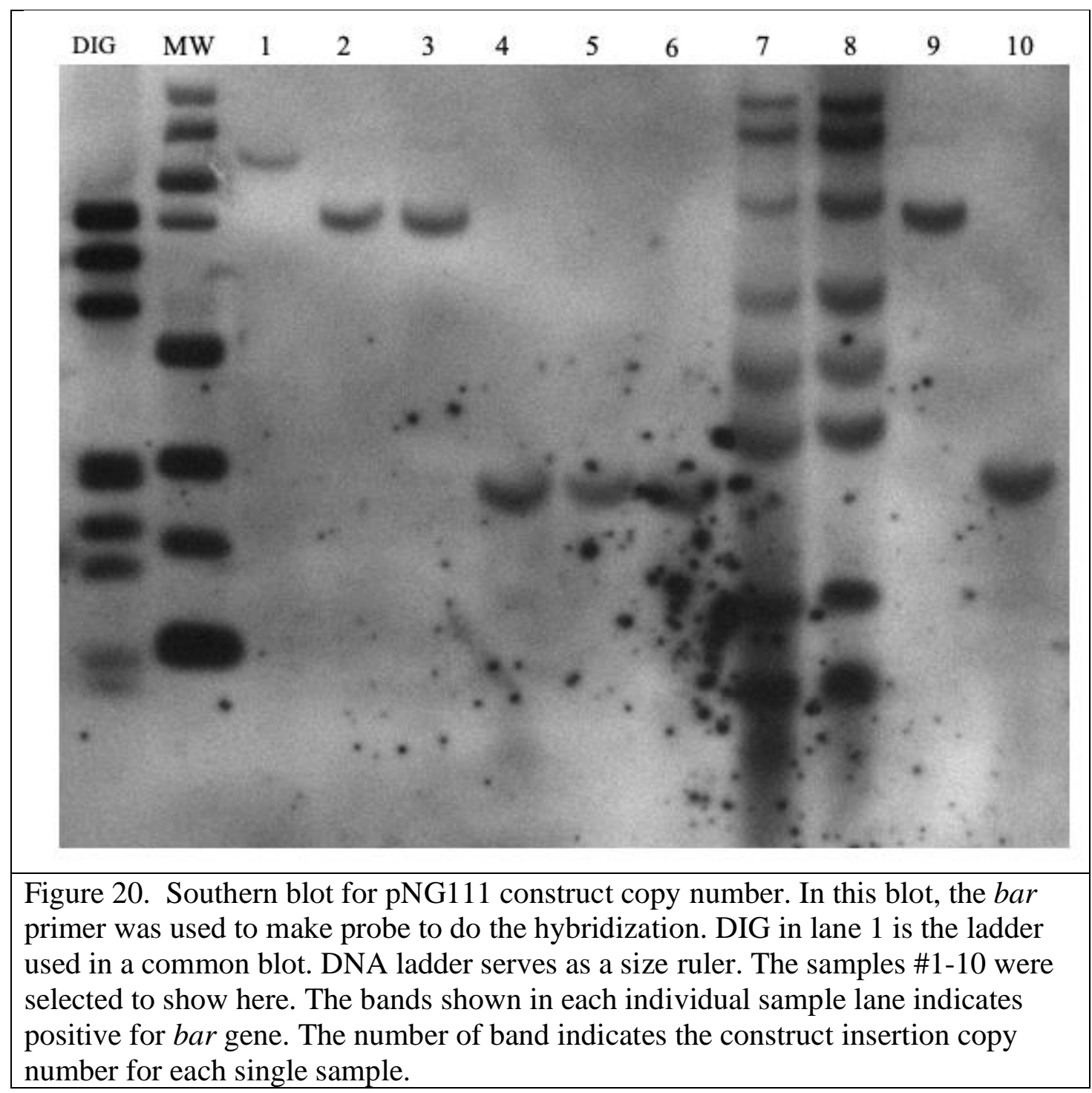

Transgenic plants which had been previously shown to have the bar, gfp, and TaCas 9 genes from pNG111 were used to observe GFP in $\mathrm{T}_{0}$ and $\mathrm{T}_{1}$ plants. The presence of the $g f p$ cassette had been confirmed by PCR (Figure 18). The $g f p$ gene is driven by the PvUbil promoter which is fused to the 5' untranslated region (UTR) and the PvUbil intron1 ligated to the $m G F P$ coding sequence (CDS) gene and the Psrbc S E9 Termination sequence and serves as a constitutively expressed visible marker. The expression of the $g f p$ gene was detected using a Zeiss Discovery v20 microscope. 
Root tips collected from To plants were used to test for GFP expression (Figure 21A).

$\mathrm{T}_{1}$ immature embryos growing in the panicles of selfed $\mathrm{T}_{0}$ plant also indicate a positive result for the GFP expression in segregating plants (Figure 21B). Root tips collected from wild type sorghum served negative control (Figure 21C.), show no fluorescence from GFP or autofluorescence.

\begin{tabular}{|l|}
\hline A B \\
\hline $\begin{array}{l}\text { Figure 21. GFP expression analysis. A. Root tip collected from a transgenic To plant } \\
\text { which had been previously shown to have the bar, gfp, and TaCas9 genes from } \\
\text { pNG111 observed using a Zeiss Discovery v20 B. T1 immature embryos were } \\
\text { harvested from mature To transgenic plants with the pNG108 vector showing } \\
\text { positive GFP fluorescence. C. Root tip from a non-transformed wild type BTx430 } \\
\text { sorghum plant shows no GFP florescence or autofluorescence and serves as negative } \\
\text { control. }\end{array}$ \\
\hline
\end{tabular}

\section{Discussion}

The significance of cereal crops to global agriculture, the economy, food security and international stability is well documented and widely understood. With the dramatic increase of the human population over the previous three decades, many consequences have been observed, including; climate change resulting in droughts, floods and fires, loss of habitat and a decrease in available arable land, decrease in water availability, resulting in a threat to global food security. In addition there has been a rise in the consumption of many natural resources including energy, resulting for a need to increase research on renewable bioenergy (Belide et al. 2017). Sorghum is a significant crop globally for food feed and bioenergy. In addition, the functional 
development of a genome-level knowledge base linking genes to phenotypes through the use of transgenics in sorghum is critical to understanding fundamental physiological functions important to crop improvement. Therefore, the capability to create, test and cultivate transgenics has enabled some of the most innovative and important scientific discoveries and agricultural achievements over the last three decades.

Thus, sorghum transformation for crop improvement is central to future agricultural enhancement. The goal here was to produce a transgenic sorghum line that would be used to test whether stably expressed TaCas9 would be useful for future genome editing functions using CRISPR sgRNAs in subsequent transformations. To address this problem, transgenic sorghum lines were produced using a vector that contained cassettes to express the bar, $g f p$ and TaCas9 genes (pNG111) and a second vector (pNG108) containing only the bar and $g f p$ genes as a negative control for the TaCas9.

Stable transgenic sorghum lines were developed using Agrobacteriummediated transformation using the pNG111 and pNG108 vectors and bialaphos selection. The plants were grown to maturity under greenhouse conditions and selfed to produce $\mathrm{T}_{1}$ seeds. The frequency of sorghum transformation with these two constructs is quite low and there are still experiments in process with the pNG108 vector to increase the number of independent events. This inefficiency in production of the desired outcome is explained primarily by the long term protocols for transformation (9-12 months to $\mathrm{T}_{1}$ seed). The regeneration frequency for the two constructs are less than $1 \%$ (see Table 1). This is not an unusual situation in sorghum 
transformation biology and is probably not construct-specific. Sorghum is referred to as a recalcitrant plant for plant transformation. The transformation protocol for sorghum exhibits low efficiency yet highly reliability. If enough effort is put into these experiments adequate numbers of transgenics will be recovered. The low frequency of successful transformation indicates that the protocol of plant transformation still needs improvement.

The transformation procedure used for sorghum in the research presented in this thesis requires using cv BTx430, because of collaborators restrictions, and selection with the bar gene for bialaphos resistance. The research presented here show that the bar gene does confer resistance to bialaphos during the selection phase of the transformation process without any escapes. Also, this research show the resistance to bialaphos in the 'paint assay' is valuable for confirming the presence of bar gene expression. These results were confirmed by PCR for the bar gene with $100 \%$ fidelity.

During this research the pNG108 and pNG111 constructs were successfully introduced into sorghum and mature fertile plants were recovered The PCR results for pNG111 clearly show the presence of the introduced vector on all To plants for the bar, gfp and TaCas9 genes, with the one exception for event \#1 using pNG111. While all samples tested positive for the bar gene, event \#1 for pNG111 was also PCR positive for $\operatorname{Ta} \operatorname{Cas} 9$ genes, but this event tested negative for $g f p$. The most reasonable explanation for this anomaly is that the $g f p$ gene was truncated during transformation. As shown (Figure 13), the mGFP CDR is located near the 5' end of the T-DNA and close to T-DNA left border. This position has been shown be susceptible to deletion during T-DNA integration (Che et al. 2018). The Southern blot analysis showed that 
the majority of events are single gene copy integrations, while two show multiple copy insertions. This is significant because previous studies have shown expression and inheritance complications in plants with multiple copy insertions (Belide et al. 2017). For this reason only events with single gene copy insertions will be used in future phenotypic analysis. The results for pNG108 show all To plants for event \#1 for the bar, and gfp genes as expected. Transformation experiments using pNG108 are also still in process to increase the number of events.

The expression of TaCas9 will need to be confirmed by Western blot analysis in future evaluations of these lines. After the molecular confirmation of presence and expression of TaCas9 gene cassette, guide RNAs will be designed by our collaborators in the Voytas Lab at the University of Minnesota and delivered into $\mathrm{T}_{1}$ immature embryos via particle bombardment. The transferred guide RNAs would be used to quantitatively determine the efficiency of CRISPR/Cas9 in sorghum.

These lines will be used in future experiments to characterize the efficiency of genome editing in the presence of stably expressed TaCas9. For example, one experiment would be to use the pNG111 line to determine the frequency of conversion of the $g f p$ sequence to $b f p$. This conversion requires two single amino acid changes (Glaser et al. 2016) and could be visualized using confocal microscopy and quantitated. (see Figure Legends in Supplemental Information). Despite tremendous improvements in plant transformation in recent years (Lowe et al. 2018,2019) sorghum transformation remains a major bottleneck and is still far from routine (Altpeter et al. 2016; Kausch et al. 2019). The procedure for sorghum transformation is labor and material expensive and requires significant laboratory expertise. Recently a program 
has been established to focus specifically on transformation technology improvement across a wide range of species (Gordon-Kamm, personal communication) with the overall goal to "bring transformation to the masses". This program seeks to develop protocols that will allow any researcher in capable laboratories to conduct routine plant transformation for research purposes. 


\section{APPENDICES:}

Table 1. Media Specifications Used for Sorghum Transformation

\begin{tabular}{|c|c|c|c|c|c|c|}
\hline \multicolumn{7}{|c|}{ Sorghum media components (per liter) } \\
\hline Componenta & Infection & $\begin{array}{c}\text { Co- } \\
\text { cultivation }\end{array}$ & Resting & $\begin{array}{c}\text { Callus } \\
\text { proliferation }\end{array}$ & R-I & R-II \\
\hline MS salts & $2.15 \mathrm{~g}$ & $2.15 \mathrm{~g}$ & $4.3 \mathrm{~g}$ & $4.3 \mathrm{~g}$ & $4.3 \mathrm{~g}$ & $2.15 \mathrm{~g}$ \\
\hline MES & & $0.5 \mathrm{~g}$ & $0.5 \mathrm{~g}$ & $0.5 \mathrm{~g}$ & $0.5 \mathrm{~g}$ & \\
\hline L-Proline & & $0.7 \mathrm{~g}$ & & & $0.7 \mathrm{~g}$ & \\
\hline Glucose & $36 \mathrm{~g}$ & $10 \mathrm{~g}$ & & & & \\
\hline Sucrose & $68.5 \mathrm{~g}$ & $20 \mathrm{~g}$ & $30 \mathrm{~g}$ & $30 \mathrm{~g}$ & $60 \mathrm{~g}$ & $30 \mathrm{~g}$ \\
\hline $\begin{array}{c}2,4-\mathrm{D}, \\
1 \mathrm{mg} / \mathrm{ml}\end{array}$ & $1.5 \mathrm{ml}$ & $2 \mathrm{ml}$ & $2 \mathrm{ml}$ & $1.5 \mathrm{ml}$ & & \\
\hline Agar & & $8 \mathrm{~g}$ & & & $8 \mathrm{~g}$ & \\
\hline Phytagel & & & $2.5 \mathrm{~g}$ & $2.5 \mathrm{~g}$ & & $2.5 \mathrm{~g}$ \\
\hline $\begin{array}{c}\mathrm{pH}(\mathrm{HCl} / \mathrm{KO} \\
\mathrm{H})\end{array}$ & 5.2 & 5.8 & 5.8 & 5.8 & 5.6 & 5.6 \\
\hline $\begin{array}{c}\text { B5(vitamin), } \\
100 x\end{array}$ & $10 \mathrm{ml}$ & $10 \mathrm{ml}$ & $10 \mathrm{ml}$ & $10 \mathrm{ml}$ & & \\
\hline $\begin{array}{c}\text { Acetosyring } \\
\text { one, } 100 \\
\text { mM }\end{array}$ & $1 \mathrm{ml}$ & $1 \mathrm{ml}$ & & & & \\
\hline $\begin{array}{c}\text { Ascorbic } \\
\text { acid }\end{array}$ & & $10 \mathrm{mg}$ & $10 \mathrm{mg}$ & & & \\
\hline $\begin{array}{l}\text { Casamino } \\
\text { acids }\end{array}$ & $1 \mathrm{~g}$ & & & & & \\
\hline Asparagine & & & $0.15 \mathrm{~g}$ & & & \\
\hline $\begin{array}{c}\text { Coconut } \\
\text { water }\end{array}$ & & & $100 \mathrm{ml}$ & & & \\
\hline Timentin & $150 \mathrm{mg}$ & $150 \mathrm{mg}$ & $150 \mathrm{mg}$ & $150 \mathrm{mg}$ & & \\
\hline $\begin{array}{c}\text { Zeatin, } 1 \\
\mathrm{mg} / \mathrm{ml}\end{array}$ & & & & & $0.5 \mathrm{ml}$ & \\
\hline $\begin{array}{l}\text { IAA, } 1 \\
\mathrm{mg} / \mathrm{ml}\end{array}$ & & & & & $1 \mathrm{ml}$ & \\
\hline $\begin{array}{c}\mathrm{ABA}, 0.025 \\
\mathrm{mg} / \mathrm{ml}\end{array}$ & & & & & $1 \mathrm{ml}$ & \\
\hline $\begin{array}{c}\text { TDZ, } 0.5 \\
\mathrm{mg} / \mathrm{ml}\end{array}$ & & & & & $0.2 \mathrm{ml}$ & \\
\hline $\begin{array}{l}\text { IBA, } 1 \\
\mathrm{mg} / \mathrm{ml}\end{array}$ & & & & & & $\begin{array}{c}0.25 \\
\mathrm{ml}\end{array}$ \\
\hline $\begin{array}{c}\text { NAA, } 1 \\
\text { g/ml }\end{array}$ & & & & & & $\begin{array}{c}0.25 \\
\mathrm{ml}\end{array}$ \\
\hline $\begin{array}{c}\text { MS vitamin, } \\
1000 x\end{array}$ & & & & & $1 \mathrm{ml}$ & $1 \mathrm{ml}$ \\
\hline
\end{tabular}




\begin{tabular}{|c|c|c|c|c|c|c|}
\hline $\begin{array}{c}\text { PVPP (1\% } \\
\text { final) }\end{array}$ & & $10 \mathrm{~g}$ & $10 \mathrm{~g}$ & $10 \mathrm{~g}$ & $10 \mathrm{~g}$ & $5 \mathrm{~g}$ \\
\hline $\begin{array}{c}\text { Sterilization } \\
\text { procedure }\end{array}$ & Filter & $\begin{array}{c}\mathrm{A} / \mathrm{C} \\
20 \mathrm{~min}\end{array}$ & $\begin{array}{c}\mathrm{A} / \mathrm{C} \\
20 \mathrm{~min}\end{array}$ & $\begin{array}{c}\mathrm{A} / \mathrm{C} \\
20 \mathrm{~min}\end{array}$ & $\begin{array}{c}\mathrm{A} / \mathrm{C} 20 \\
\mathrm{~min}\end{array}$ & $\begin{array}{c}\mathrm{A} / \mathrm{C} \\
20 \mathrm{~min}\end{array}$ \\
\hline
\end{tabular}

aABA, abscisic acid; 2,4-D, 2,4-dichlorophenoxyacetic acid; IAA, indole-3-acetic acid; IBA, indole-3-butyric acid (auxin); MES, morpholine-

4-ethanesulfonic acid; MS salts, Murashige and Skoog basal salt mixture; MS

vitamin, Murashige and Skoog basal medium with vitamins;

NAA, 1-naphthaleneacetic acid; PVPP, polyvinylpolypyrrolidone; TDZ,

thidiazuron.

R: Regeneration; A/C: Autoclave.

Table 1. The sorghum medium information.

Table 2. PCR Primer Specifications Used to Analyze the bar, citrine, gfp, and TaCas9 genes

\begin{tabular}{|l|l|l|l|l|}
\hline Oligo & Length & tm & GC $\%$ & Sequence \\
\hline Forward & 20 & 60.03 & 55.00 & GGATCTACCATGAGCCCAGA \\
\hline Reverse & 20 & 60.00 & 55.00 & GAAGTCCAGCTGCCAGAAAC \\
\hline Product Size: 513
\end{tabular}

\begin{tabular}{|l|l|l|l|l|}
\hline Oligo & Length & tm & GC $\%$ & Sequence \\
\hline Forward & 20 & 60.04 & 50.00 & ACGTAAACGGCCACAAGTTC \\
\hline Reverse & 20 & 60.41 & 50.00 & ATGCCGTTCTTCTGCTTGTC \\
\hline Product Size: 421 \\
\hline
\end{tabular}

\begin{tabular}{|l|l|l|l|l|}
\hline Oligo & Length & tm & GC $\%$ & Sequence \\
\hline Forward & 20 & 60.05 & 50.00 & TCAAGGAGGACGGAAACATC \\
\hline Reverse & 20 & 59.97 & 50.00 & AAAGGGCAGATTGTGTGGAC \\
\hline Product Size: 234
\end{tabular}

\begin{tabular}{|l|l|l|l|l|}
\hline Oligo & Length & tm & GC $\%$ & Sequence \\
\hline Forward & 20 & 60.01 & 55.00 & AGACCGTGAAGGTTGTGGAC \\
\hline Reverse & 20 & 60.00 & 55.00 & ACCTGGTGAGGACCTTGTTG \\
\hline Product Size: 421 \\
\hline
\end{tabular}


Figure 1. Vector map for pNG111

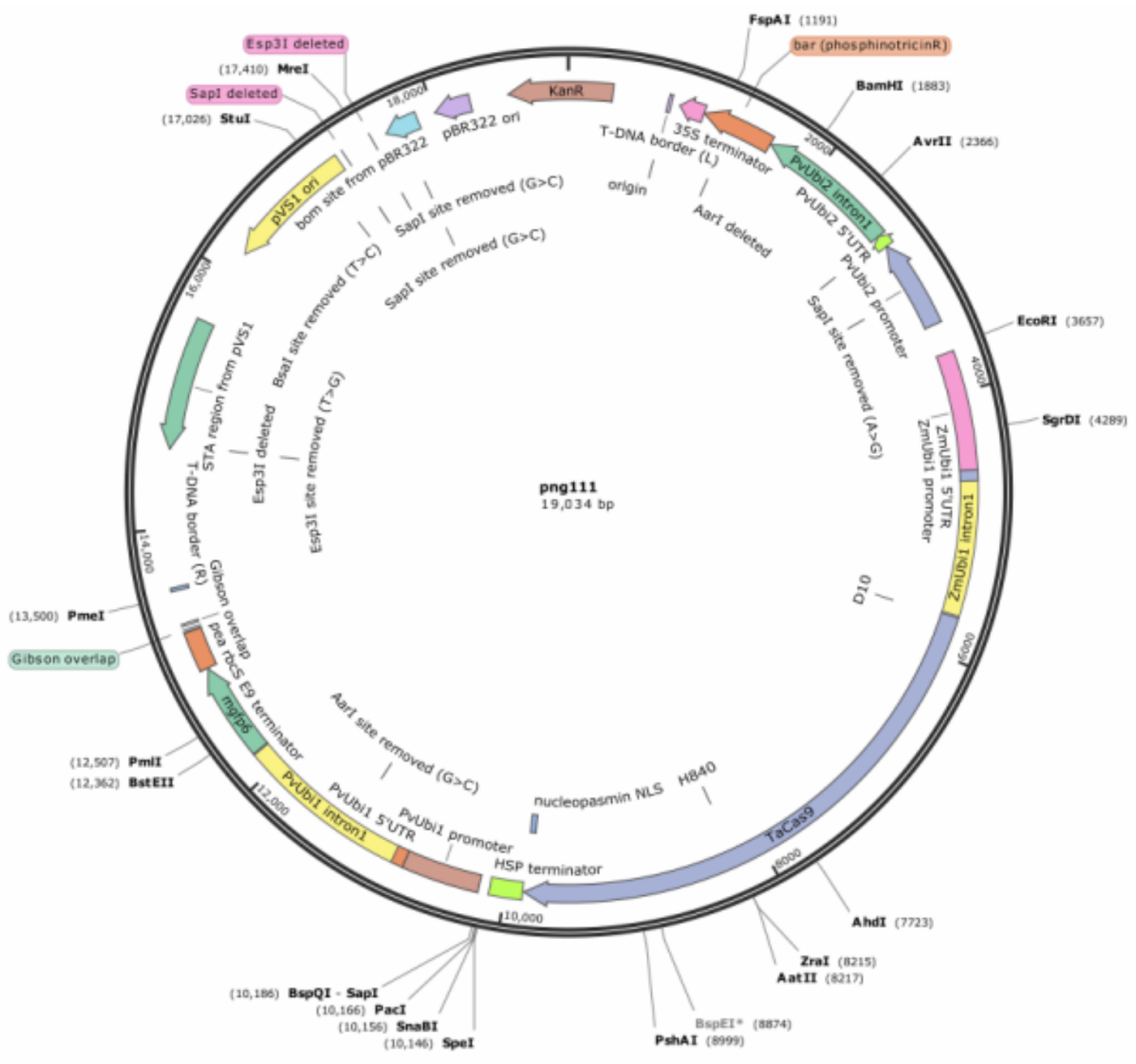

\section{pNG111-ZmUbi::TaCas9_PvUbi::1GFP}

This vector should constitutively express $\operatorname{Ta} \operatorname{Cas} 9$ and $g f p$. This means that we can analyze for $g f p$ and assume that the TaCas 9 cassette is also present because they are linked. In addition presence of both $T a C a s 9$ and $g f p$ can be verified molecularly in small plants during regeneration. GFP expression can be analyzed through the development cycle of the transgenic lines from callus to plants. In addition, we can design guide RNAs which will edit the $g f p$ gene to convert it to $b f p$. The result should appear as blue foci against a GFP background. The frequency of edits can be quantitatively determined. This information will be extremely useful to predict editing frequencies in studies where a visual marker is not involved. 
Figure 2. Vector map for pNG108

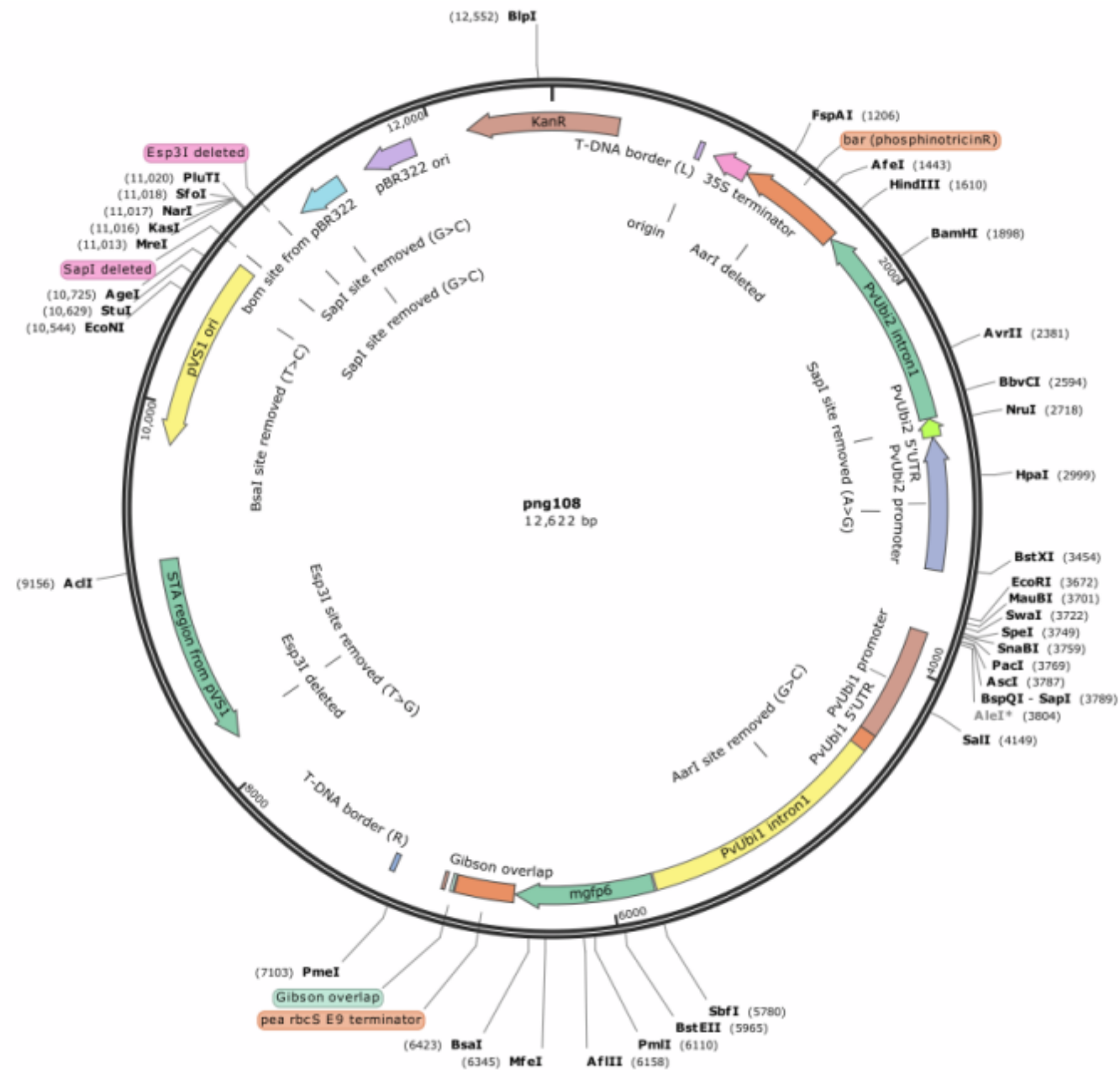

\section{pNG108- PvUbi1::GFP}

This vector should provide a negative control exhibiting constitutive expression of $g f p$, but without the presence of TaCas9. Therefore when the same guide RNAs (used in pNG111) are delivered, no BFP expression should be observed. 


\section{BIBLIOGRAPHY}

Altpeter F, Springer NM, Bartley LE, Blechl A, Brutnell TP, Citovsky V, Conrad L, Gelvin SB, Jackson D, Kausch AP, Lemaux PG, Medford JI, Orozo-Cardenas M, Tricoli D, VanEck J, Voytas DF, Walbot V, Wang K, Zhang ZJ, Stewart, C. Neal (2016) Advancing Crop Transformation in the Era of Genome Editing. The Plant Cell. doi:10.1105/tpc.16.00196

Belide S, Vanhercke T, Petrie JR, Singh SP (2017) Robust genetic transformation of sorghum (Sorghum bicolor L.) using differentiating embryogenic callus induced from immature embryos. Plant Methods 13:109. doi:10.1186/s13007017-0260-9

Bevan MW, Mason SE, Goelet P (1985) Expression of tobacco mosaic virus coat protein by a cauliflower mosaic virus promoter in plants transformed by Agrobacterium. EMBO J 4 (8):1921-1926

Biolabs NEnd (2014) CRISPR/Cas9 \& Targeted Genome Editing: New Era in Molecular Biology. https://www.neb.com/tools-and-resources/featurearticles/crispr-cas9-and-targeted-genome-editing-a-new-era-in-molecularbiology.

Bortesi L, Fischer R (2015) The CRISPR/Cas9 system for plant genome editing and beyond. Biotechnology Advances 33 (1):41-52. doi:https://doi.org/10.1016/j.biotechadv.2014.12.006

Che P, Anand A, Wu E, Sander JD, Simon MK, Zhu W, Sigmund AL, Zastrow-Hayes G, Miller M, Liu D, Lawit SJ, Zhao ZY, Albertsen MC, Jones TJ (2018) Developing a flexible, high-efficiency Agrobacterium-mediated sorghum transformation system with broad application. Plant Biotechnol J 16 (7):13881395. doi:10.1111/pbi.12879

Chen J, Dellaporta S (1994) Urea-based plant DNA miniprep. In: Freeling M, Walbot V (eds) The Maize Handbook. Springer-Verlag, New York

Clasen BM, J. ST, Song L, L. DZ, Jin L, Frederic C, Redeat T, Shawn D, E. RE, Aurelie D, Andrew C, Ann Y, Adam R, William H, J. BN, Luc M, F. VD, Feng Z (2015) Improving cold storage and processing traits in potato through targeted gene knockout. Plant Biotechnology Journal 14 (1):169-176. doi:doi:10.1111/pbi.12370

Cong L, Ran FA, Cox D, Lin S, Barretto R, Habib N, Hsu PD, Wu X, Jiang W, Marraffini LA, Zhang F (2013) Multiplex Genome Engineering Using CRISPR/Cas Systems. Science 339 (6121):819-823.

doi:10.1126/science. 1231143 
Council for Agricultural Science and Technology (CAST) (2018) Genome Editing in Agriculture: Methods, Applications, and Governance - A paper in the series on The Need for Agricultural Innovation to Sustainably Feed the World by 2050. Issue Paper 60 edn. CAST, Ames, Iowa

De Block M, Herrera-Estrella L, Van Montagu M, Schell J, Zambryski P (1984) Expression of foreign genes in regenerated plants and in their progeny. EMBO $J 3(8): 1681-1689$

Devos Y, Cougnon M, Vergucht S, Bulcke R, Haesaert G, Steurbaut W, Reheul D (2008) Environmental impact of herbicide regimes used with genetically modified herbicide-resistant maize. Transgenic Res 17 (6):1059-1077. doi:10.1007/s11248-008-9181-8

Do PT, Lee H, Nelson-Vasilchik K, Kausch A, Zhang ZJ (2018) Rapid and Efficient Genetic Transformation of Sorghum via Agrobacterium-Mediated Method. Curr Protoc Plant Biol 3 (4):e20077. doi:10.1002/cppb.20077

FAO/IAEA (2014) Plant Breeding and Genetics, Available from: Food and Agricultural Organization, International Atomic Energy Agency Division of Nuclear Techniques in Agriculture.

Ferreira SA, Pitz KY, Manshardt R, Zee F, Fitch M, Gonsalves D (2002) Virus Coat Protein Transgenic Papaya Provides Practical Control of Papaya ringspot virus in Hawaii. Plant Dis 86 (2):101-105. doi:10.1094/PDIS.2002.86.2.101

Fraley RT, Rogers SG, Horsch RB, Sanders PR, Flick JS, Adams SP, Bittner ML, Brand LA, Fink CL, Fry JS, Galluppi GR, Goldberg SB, Hoffmann NL, Woo SC (1983) Expression of bacterial genes in plant cells. Proc Natl Acad Sci U S A 80 (15):4803-4807. doi:10.1073/pnas.80.15.4803

Gao H, Jeff S, Meizhu Y, Spencer J, Vesna D, G. NM, Ande W, Dennis B, Carl FS, Derek J, Alexander LL (2010) Heritable targeted mutagenesis in maize using a designed endonuclease. The Plant Journal 61 (1):176-187. doi:doi:10.1111/j.1365-313X.2009.04041.x

Glaser A, McColl B, Vadolas J (2016) GFP to BFP Conversion: A Versatile Assay for the Quantification of CRISPR/Cas9-mediated Genome Editing. Mol Ther Nucleic Acids 5 (7):e334. doi:10.1038/mtna.2016.48

Hayward AP, Moreno MA, Howard TP, 3rd, Hague J, Nelson K, Heffelfinger C, Romero S, Kausch AP, Glauser G, Acosta IF, Mottinger JP, Dellaporta SL (2016) Control of sexuality by the sk1-encoded UDP-glycosyltransferase of maize. Sci Adv 2 (10):e1600991. doi:10.1126/sciadv.1600991 
Jiang W, Zhou H, Bi H, Fromm M, Yang B, Weeks DP (2013) Demonstration of CRISPR/Cas9/sgRNA-mediated targeted gene modification in Arabidopsis, tobacco, sorghum and rice. Nucleic Acids Research 41 (20):e188-e188. doi:10.1093/nar/gkt780

Jiao Y, Lee YK, Gladman N, Chopra R, Christensen SA, Regulski M, Burow G, Hayes C, Burke J, Ware D, Xin Z (2018) MSD1 regulates pedicellate spikelet fertility in sorghum through the jasmonic acid pathway. Nat Commun 9 (1):822. doi:10.1038/s41467-018-03238-4

Jinek M, Chylinski K, Fonfara I, Hauer M, Doudna JA, Charpentier E (2012) A Programmable Dual-RNA-Guided DNA Endonuclease in Adaptive Bacterial Immunity. Science 337 (6096):816-821. doi:10.1126/science.1225829

Kausch AP, Nelson-Vasilchik K, Hague J, Mookkan M, Quemada H, Dellaporta S, Fragoso C, Zhang ZJ (2019) Edit at will: Genotype independent plant transformation in the era of advanced genomics and genome editing. Plant Science 281:186-205. doi:https://doi.org/10.1016/j.plantsci.2019.01.006

Li Q, Liu B (2017) Genetic regulation of maize flower development and sex determination. Planta 245 (1):1-14. doi:10.1007/s00425-016-2607-2

Lowe K, La Rota M, Hoerster G, Hastings C, Wang N, Chamberlin M, Wu E, Jones T, Gordon-Kamm W (2018) Rapid genotype “independent” Zea mays L. (maize) transformation via direct somatic embryogenesis. In Vitro Cellular \& Developmental Biology - Plant 54 (3):240-252. doi:10.1007/s11627-018-99052

Lowe K, Wu E, Wang N, Hoerster G, Hastings C, Cho M-J, Scelonge C, Lenderts B, Chamberlin M, Cushatt J, Wang L, Ryan L, Khan T, Chow-Yiu J, Hua W, Yu M, Banh J, Bao Z, Brink K, Igo E, Rudrappa B, Shamseer PM, Bruce W, Newman L, Shen B, Zheng P, Bidney D, Falco SC, RegisterIII JC, Zhao Z-Y, $\mathrm{Xu}$ D, Jones TJ, Gordon-Kamm WJ (2016) Morphogenic Regulators Baby boom and Wuschel Improve Monocot Transformation. The Plant Cell 28 (9):1998-2015. doi:10.1105/tpc.16.00124

Mali P, Yang L, Esvelt KM, Aach J, Guell M, DiCarlo JE, Norville JE, Church GM (2013) RNA-Guided Human Genome Engineering via Cas9. Science 339 (6121):823-826. doi:10.1126/science.1232033

Meyer RS, DuVal AE, Jensen HR (2012) Patterns and processes in crop domestication: an historical review and quantitative analysis of 203 global food crops. New Phytol 196 (1):29-48. doi:10.1111/j.1469-8137.2012.04253.x 
Mookkan M, Nelson-Vasilchik K, Hague J, Kausch A, Zhang ZJ (2018) Morphogenic Regulator-Mediated Transformation of Maize Inbred B73. Current Protocols in Plant Biology 3 (4):e20075. doi:10.1002/cppb.20075

Mookkan M, Nelson-Vasilchik K, Hague J, Zhang ZJ, Kausch AP (2017) Selectable marker independent transformation of recalcitrant maize inbred B73 and sorghum P898012 mediated by morphogenic regulators BABY BOOM and WUSCHEL2. Plant Cell Reports 36 (9):1477-1491. doi:10.1007/s00299-0172169-1

Nakade S, Yamamoto T, Sakuma T (2017) Cas9, Cpf1 and C2c1/2/3-What's next? Bioengineered 8 (3):265-273. doi:10.1080/21655979.2017.1282018

Nelson-Vasilchik K, Hague J, Mookkan M, Zhang ZJ, Kausch A (2018) Transformation of Recalcitrant Sorghum Varieties Facilitated by Baby Boom and Wuschel2. Current Protocols in Plant Biology 3 (4):e20076. doi:10.1002/cppb.20076

Sander JD, Joung JK (2014) CRISPR-Cas systems for editing, regulating and targeting genomes. Nature Biotechnology 32:347. doi:10.1038/nbt.2842

https://www.nature.com/articles/nbt.2842\#supplementary-information

Schachtsiek J, Stehle F (2019) Nicotine-free, nontransgenic tobacco (Nicotiana tabacum 1.) edited by CRISPR-Cas9. Plant Biotechnol J 17 (12):2228-2230. doi:10.1111/pbi.13193

Schiml S, Puchta H (2016) Revolutionizing plant biology: multiple ways of genome engineering by CRISPR/Cas. Plant Methods 12 (1):8. doi:10.1186/s13007016-0103-0

Shukla VK, Doyon Y, Miller JC, DeKelver RC, Moehle EA, Worden SE, Mitchell JC, Arnold NL, Gopalan S, Meng X, Choi VM, Rock JM, Wu Y-Y, Katibah GE, Zhifang G, McCaskill D, Simpson MA, Blakeslee B, Greenwalt SA, Butler HJ, Hinkley SJ, Zhang L, Rebar EJ, Gregory PD, Urnov FD (2009) Precise genome modification in the crop species Zea mays using zinc-finger nucleases. Nature 459:437. doi:10.1038/nature07992

Songstad DD, Petolino JF, Voytas DF, Reichert NA (2017) Genome Editing of Plants. Critical Reviews in Plant Sciences 36 (1):1-23. doi:10.1080/07352689.2017.1281663

Thurtle-Schmidt DM, Lo TW (2018) Molecular biology at the cutting edge: A review on CRISPR/CAS9 gene editing for undergraduates. Biochem Mol Biol Educ 46 (2):195-205. doi:10.1002/bmb.21108 
Weeks DP, Spalding MH, Yang B (2016) Use of designer nucleases for targeted gene and genome editing in plants. Plant Biotechnology Journal 14 (2):483-495. doi:doi:10.1111/pbi.12448

Wu E, Lenderts B, Glassman K, Berezowska-Kaniewska M, Christensen H, Asmus T, Zhen S, Chu U, Cho MJ, Zhao ZY (2014) Optimized Agrobacterium-mediated sorghum transformation protocol and molecular data of transgenic sorghum plants. In Vitro Cell Dev Biol Plant 50 (1):9-18. doi:10.1007/s11627-0139583-z

Zhao ZY, Cai T, Tagliani L, Miller M, Wang N, Pang H, Rudert M, Schroeder S, Hondred D, Seltzer J, Pierce D (2000) Agrobacterium-mediated sorghum transformation. Plant Mol Biol 44 (6):789-798. doi:10.1023/a:1026507517182 